\title{
LA OCUPACIÓN WARI EN LOS VALLES DE PALPA, COSTA SUR DEL PERÚ
}

\author{
JOHNY ISLA CUADRADO

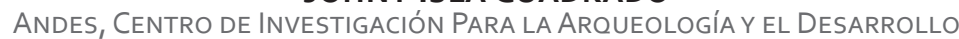 \\ isla.nasca@gmail.com \\ MARKUS REINDEL \\ COMISIÓN DE ARQUEOlOgÍA PARA CULTURAS EXTRAEUROPEAS, INSTITUTO ARQUEOLÓGICO ALEMÁN (DAI) \\ markus.reindel@dainst.de
}

\section{RESUMEN}

Recientes investigaciones en los valles de Palpa, en la parte norte de la cuenca del Río Grande de Nasca, han puesto al descubierto numerosas evidencias arqueológicas (asentamientos, estructuras funerarias, diversos materiales y restos de la vida cotidiana) que están brindando nuevas luces sobre la intensidad y la naturaleza que tuvo la ocupación Wari en la costa sur del Perú. Excavaciones puntuales realizadas en varios sitios con evidencias de ocupación Wari en los valles de Palpa, los cuales están localizados en la costa, la yunga desértica y la sierra, nos ayudan a entender el fuerte grado de integración existente entre diferentes zonas ecológicas y el interés que tuvieron los Wari para ocupar los valles de Palpa y Nasca. En este sentido, las evidencias documentadas hasta hoy en los valles de Palpa indican que la costa sur, y de modo especial la cuenca del Río Grande, tuvo un rol importante en el desarrollo de las estrategias de expansión y control de Wari en la región, lo que le permitió el acceso a recursos no existentes en la zona de Ayacucho.

Palabras Clave: Palpa, Nasca, Wari, cuenca del Río Grande, asentamientos, tumbas.

\section{ABSTRACT}

Recent research in the Palpa valleys, in the northern section of the Rio Grande of Nasca drainage, has revealed many archaeological evidences (settlements, funerary structures, diverse materials and remains of daily life). This evidence is shedding new light on the intensity and nature of the Wari occupation in the south coast of Peru. Excavations in many sites with evidence of Wari occupation in the coast, the Yunga Desertica, and the highlands, help us to understand the strong integration that existed amongst different ecological zones and the interest that motivated the Wari to occupy the Palpa and Nasca valleys. In this context, the evidence registered until now in the Palpa valleys indicated that the south coast, and specially the Rio Grande drainage, had an important role in the Wari strategy of expansion and control in the region, allowing the access to resources not existent in the Ayacucho area.

KEYWords: Palpa, Nasca, Wari, Río Grande drainage, settlements, funeray structures. 


\section{INTRODUCCIÓN}

La ocupación Wari en la costa sur del Perú es largamente conocida por las grandes cantidades de cerámica encontradas en depósitos de ofrenda por Julio C. Tello en el sitio de Pacheco, en el valle de Nasca, y por las numerosas tumbas y fardos funerarios excavados en diversos cementerios de los valles de Ica, Palpa y Nasca (Tello 1917; Strong 1957; Doëring 1958; Tello y Mejía 1967; Neüdecker 1979) (Fig. 1). Estas colecciones formaron parte importante del corpus sobre el cual se hicieron los primeros estudios estilísticos de la cerámica Wari en la costa sur, los cuales luego fueron utilizados como parámetro cronológico (Menzel 1964, 1968a, 1968b) para identificar las etapas de desarrollo que tuvo esta importante formación social durante el Horizonte Medio (600-1000 d.C.).

Luego de estos primeros descubrimientos, realizados principalmente en la primera mitad del siglo XX, los estudios sobre Wari en la región se han limitado básicamente al reconocimiento superfi-

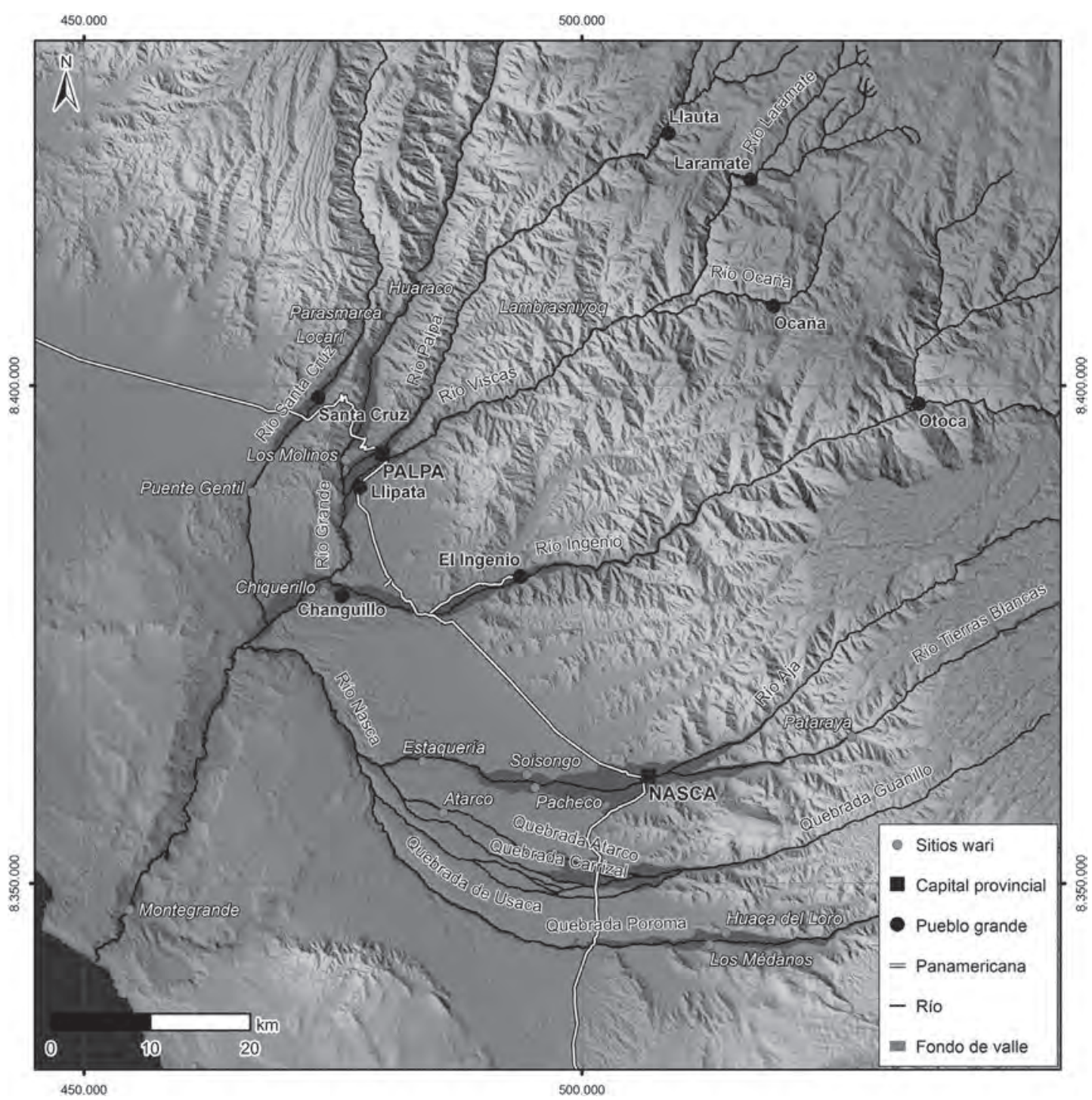

Figura 1. Mapa de la costa sur del Perú con ubicación de la cuenca del Río Grande de Nasca. 
cial de algunos sitios y cementerios dispersos en todos los valles de la cuenca del Río Grande (Fig. 2), ${ }^{1}$ mientras que excavaciones limitadas en el sitio de Huaca del Loro, en el valle de Las Trancas (Strong 1957), pusieron en relevancia la importancia que tuvo la ocupación Wari en la región. No obstante, debido principalmente a la falta de investigaciones sistemáticas, todavía se conoce poco sobre los sitios mismos en donde se han encontrado los materiales de filiación Wari, y menos aún sobre los me-

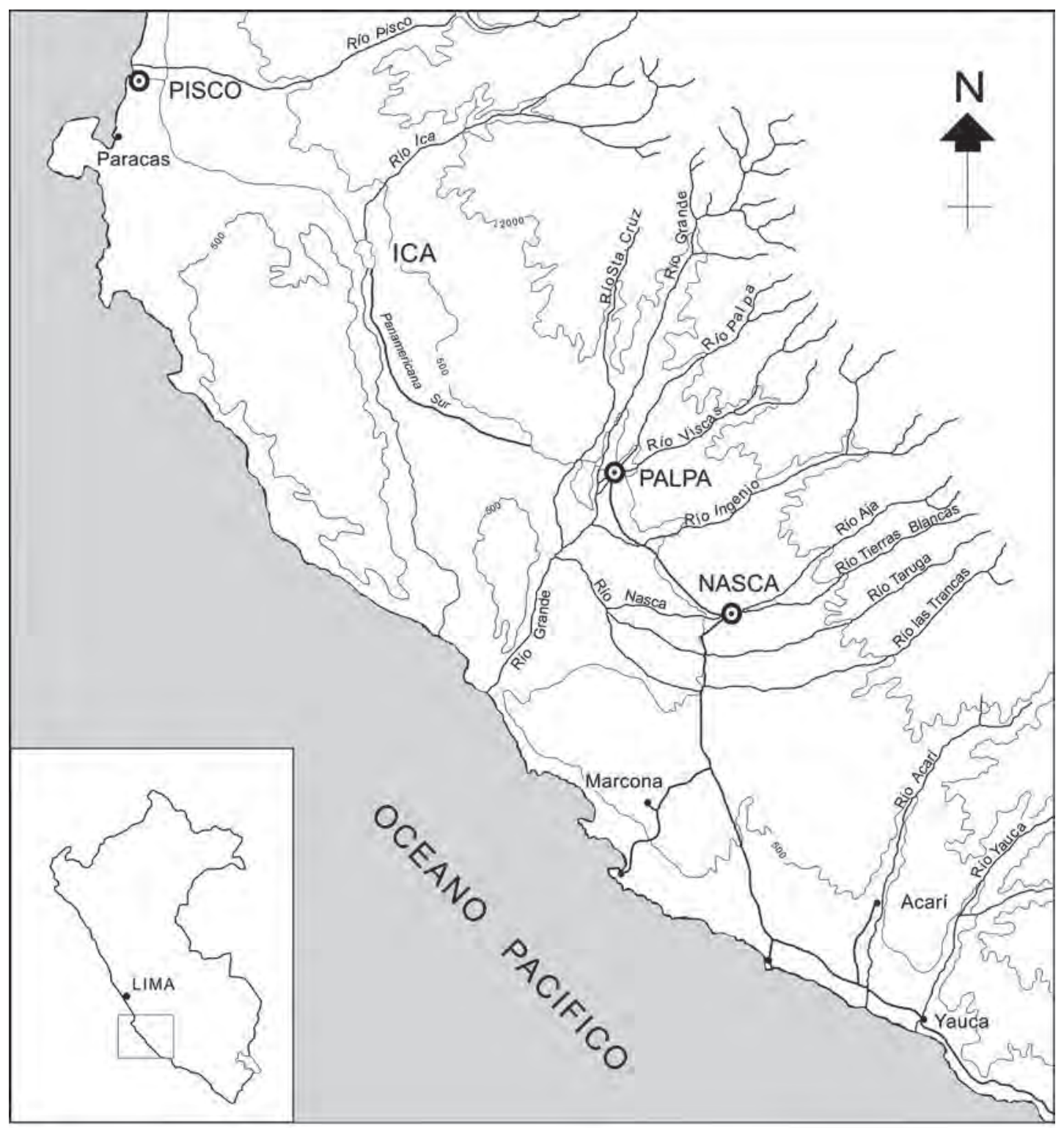

Figura 2. Mapa de la cuenca del Río Grande de Nasca con ubicación de los principales sitios Wari mencionados en el texto.

1 La cuenca del Río Grande se localiza al sur de la Región Ica, ocupando el extremo Norte del desierto de Atacama y parte de la cordillera occidental de los Andes, espacios geográficos que se encuentran al sudoeste y oeste de las regiones de Huancavelica y Ayacucho, respectivamente. 
canismos de acceso y estrategias de control que empleó el estado Wari durante su expansión hacia la costa sur. En este sentido, conviene indicar que en los últimos años Schreiber (2001) y Edwards (2010) han brindado importantes propuestas sobre estos temas, los mismos que ayudan a entender mejor la naturaleza de la ocupación Wari en la región.

Por otro lado, en el curso de los últimos quince años, como parte de las investigaciones que realiza el Proyecto Arqueológico Nasca-Palpa, dirigido por los autores de este artículo, se viene reconstruyendo el largo proceso cultural que hubo en los valles de Palpa (Reindel 2009; Isla 2010), los cuales se localizan en la parte norte de la cuenca del Río Grande. ${ }^{2}$ En el marco de este proyecto, en los primeros años de investigación se identificaron - mediante intensos trabajos de prospección y excavación - varios pequeños asentamientos, cementerios y tumbas aisladas de filiación Wari localizados en la parte media y media alta de los valles de Palpa, aunque no en número ni en tamaño comparables con los sitios que se conocen para los valles de Nasca. ${ }^{3}$ No obstante, las evidencias registradas en estos años indican claramente que estos valles, a pesar de las condiciones de aridez que soportaron durante ese tiempo, también presentan una importante ocupación Wari, la cual fue especialmente notable durante la época 2 del Horizonte Medio. En este sentido, sitios como Parasmarca, Huaraco y Lambrasniyoq parecen haber sido los centros poblados más importantes de la época en esta parte de los valles de Palpa. ${ }^{4}$

Asimismo, en los últimos cinco años, como resultado de la ampliación de las investigaciones del Proyecto Nasca-Palpa hacia la parte alta de los valles de Palpa, en la sierra misma, en una zona donde hay una mayor disponibilidad de agua, campos de cultivo y áreas para el pastoreo, se ha llegado a registrar un importante número de asentamientos, cementerios, tumbas aisladas y corrales que indican que la ocupación Wari en ese lugar fue más estable y permanente..$^{5}$ Al tratarse de una zona donde el acceso a los recursos era más seguro y a la vez ubicada en un punto intermedio para llegar a la costa, los principales sitios establecidos en dicha zona debieron constituir los centros desde donde se planificó y dirigió la penetración a los valles costeños. Sitios como Mauka Llaqta, Huayuncalla, Chilcapuquio y Palmadera parecen haber sido los centros poblados más importantes de la época en la parte alta de los valles de Palpa.

En efecto, recientes excavaciones realizadas en Huayuncalla, han puesto al descubierto los restos de un gran centro poblado donde se encuentran numerosas construcciones circulares de vivienda, recintos de planta rectangular relacionados con la producción de bienes artesanales, así como estructuras funerarias en donde se llevaron a cabo singulares rituales mortuorios. Las evidencias documentadas indican que en el sitio residía un grupo de élite de la sociedad Wari junto con un importante número de habitantes, cuya principal actividad se relacionaba con la agricultura y la producción de bienes.

Asimismo, los trabajos de prospección en la zona de la sierra han permitido identificar dos caminos de larga distancia que bajan hacia la costa por los valles de Palpa y Viscas. Estos caminos conectan importantes sitios Wari en su ruta entre la sierra y la costa, por lo cual es posible sugerir que ambos fueron establecidos en ese tiempo.

2 Como valles de Palpa se conocen a los oasis que forman los ríos Santa Cruz, Grande, Palpa y Viscas, los cuales descienden desde la vertiente occidental de los Andes hacia la costa, siguiendo una dirección que va de noreste a sudoeste.

3 Estas diferencias podrían deberse a las distintas estrategias de penetración y control que se utilizaron para ambas zonas de la cuenca del Río Grande, y también a la evidente mayor posibilidad de obtener agua del subsuelo durante ese tiempo en los valles de Nasca.

4 Sitios como El Manantial o La Máquina y Palpa — localizado justo debajo de la actual ciudad de Palpatambién parecen haber tenido un rol dominante en este tiempo, aunque éstos han sido seriamente afectados por los huaqueos o destruidos por el avance urbano.

5 Esta zona, conocida como las cabezadas, se encuentra entre los 2000 y $4000 \mathrm{msnm}$ y se localiza en la parte occidental de la provincia de Lucanas (Ayacucho). 


\section{Los valles de Palpa durante el Horizonte Medio}

Antes de la ocupación Wari en la costa sur, los valles de Palpa y Nasca conformaban el área nuclear en donde se desarrolló la famosa cultura Nasca (50-650 d.C.), la cual es conocida mundialmente por su fina cerámica polícroma, sus elaborados textiles y sobre todo por sus impresionantes geoglifos dibujados en las pampas desérticas de Palpa y Nasca (Silverman y Proulx 2002; Lambers 2006; Reindel et al. 2006). Las evidencias arqueológicas indican que durante ese tiempo la sociedad Nasca alcanzó altos niveles de desarrollo político y social, los cuales se sustentan en importantes innovaciones tecnológicas - como la construcción de los acueductos - que permitieron afrontar y superar las dificultades que presentaba el medio desértico (Reindel e Isla 2001).

Este floreciente desarrollo, particularmente notable durante la época Nasca Medio (300-440 d.C.), se vio seriamente afectado durante la época Nasca Tardío (440-640 d.C.) por un intenso proceso de desertificación que hizo colapsar las estructuras de la sociedad. ${ }^{6}$ Durante esta época, con la ocurrencia de sequías cada vez más prolongadas, la mayor parte de la población abandonó la parte baja y media de los valles y se fue trasladando hacia las partes más altas, en donde, si bien habían menos áreas de cultivo, el acceso al agua en los ríos era más seguro y estable. ${ }^{7}$ En este contexto surgieron grandes asentamientos como Parasmarca y Huaraco, ubicados en la parte media alta del valle del Río Grande, los cuales al parecer funcionaron como centros administrativos de la época. Justamente en estos sitios se observa luego, durante la época 2 del Horizonte Medio, importantes evidencias relacionadas con la ocupación Wari en la zona.

La severa crisis hídrica que afectó la región al inicio del Horizonte Medio provocó el colapso de la sociedad Nasca, cuya población —incluyendo a la élite dominante_ fue lentamente absorbida por la creciente influencia Wari, la cual inició su expansión hacia la costa sur justamente alrededor del año 600 d.C. Es así que, como parte de este proceso y de la reorganización sociopolítica emprendida por Wari durante el Horizonte Medio, en toda la cuenca del río Grande y en los valles vecinos ocurrieron cambios notables en el patrón de asentamiento, en la producción artesanal y en las costumbres funerarias.

En cuanto al patrón de asentamiento, durante este tiempo hubo una notable disminución en el número de asentamientos con respecto a la época Nasca y en general se puede decir que hubo un marcado descenso en el número de habitantes. ${ }^{8}$ En este contexto, entre unos pocos sitios de vivienda registrados en la parte media y media alta de los valles de Palpa, los sitios de Huaraco y Lambrasniyoq fueron los que detentaron el rol de centros políticos importantes durante la época 2. ${ }^{9}$ Una situación parecida ocurrió en los valles de Nasca, donde los sitios que tuvieron el rol de centros principales fueron Pacheco y Huaca del Loro durante la época 1 y Pataraya durante la época 2 (Schreiber 2001; Edwards 2010). Esta situación, como se verá más adelante, fue distinta en la parte alta de los valles de Palpa.

6 Estudios del paleoclima realizados en los valles de Palpa indican que durante el desarrollo de la cultura Nasca empezó un lento proceso de desertificación en la región, el cual se hizo más intenso durante la época Nasca medio y fue particularmente severo al final de la época Nasca Tardío, alrededor del año 600 d.C. (Eitel et al. 2005; Eitel y Mächtle 2009; Mächtle 2013).

7 Es posible que otros grupos también hayan migrado hacia los valles de Ica y Acarí, donde las evidencias indican que durante la época Nasca Tardío se establecieron grandes centros poblados como Pampa de La Tinguiña y Chaviña, respectivamente (Menzel 1971).

8 Solo en el valle de Las Trancas, en la parte sur de la cuenca, se nota un incremento importante en el número de sitios y de población residente durante este tiempo, destacando el sitio de Huaca del Loro, el cual funcionó como el centro político más importante a nivel local (Schreiber 2001).

9 Restos de un sitio que podría haber tenido el rol de centro principal se han registrado recientemente en Palpa, justo debajo de la ciudad actual, pero se desconocen sus dimensiones. 
Con relación a la producción artesanal, los cambios más evidentes se observan en la alfarería, donde la fina y elaborada cerámica Nasca fue reemplazada por otra más sencilla y con menos policromía, conocida como Loro (antes Nasca 8), la cual debe su nombre al sitio homónimo excavado por Strong en el valle de Las Trancas (Strong 1957). Junto con la cerámica del estilo Loro, considerado como el estilo local de la época 1 del Horizonte Medio, también hizo su aparición la cerámica del estilo Chakipampa, uno de los estilos alfareros más representativos del estado Wari, cuyo lugar de origen se encuentra en la región de Ayacucho (Knoblock 1983; Silverman 1988). ${ }^{10}$ La cerámica Chakipampa en la costa sur ha sido registrada principalmente en contextos funerarios, aunque también la hemos identificado en contextos de vivienda y residenciales en sitios como de Huaca del Loro, Estaquería, Los Molinos y Huaraco. En base a las evidencias conocidas hasta hoy, se puede decir con certeza que los estilos Loro y Chakipampa fueron contemporáneos, siendo uno de manufactura local y el otro importado, los cuales estuvieron vigentes durante toda la época 1 del Horizonte Medio. ${ }^{11}$

Durante la época 2, en la etapa de pleno dominio Wari en la región, los estilos alfareros de élite más frecuentes fueron Atarco, Viñaque y Pachacámac, a los cuales seguían los estilos Qosqopa y Huamanga, mientras que el estilo local dominante durante las épocas 2 y 3 fue Soisongo (Menzel 1964). La mayoría de estos materiales provienen de contextos funerarios registrados en diversos sitios de la cuenca del río Grande y solo unos pocos de sitios de habitación o residencia. Otra vez durante la época 3 se observa una virtual ausencia de sitios Wari en los valles de Palpa mientras que sus evidencias son particularmente notables en los valles de Nasca y Las Trancas.

Por otro lado, el patrón funerario también presenta cambios importantes con respecto al desarrollo de la cultura Nasca (Carmichael 1995, Isla 2009). En este sentido, si bien se mantuvo los mismos tipos de sepultura existente durante el desarrollo de la cultura Nasca (Isla 2001), durante el Horizonte Medio aparecen también tumbas hechas de piedra sobre la superficie del terreno o apenas bajo el nivel del mismo, las cuales presentan cámaras circulares, ovalada o cuadrangulares. Asimismo, además de los entierros individuales se observa la ocurrencia de entierros múltiples, en donde los individuos se encuentran enfardelados. Las primeras evidencias de este nuevo patrón funerario se observan en la primera época del Horizonte Medio en relación con los estilos Loro y Chakipampa, y después son frecuentes en todos los cementerios de las épocas 2 y 3 (Isla 2001).

\section{Las investigaciones del Proyecto Nasca-Palpa}

Desde 1997 un numeroso equipo de investigadores integrantes del Proyecto Nasca-Palpa viene realizando diversos estudios en los valles de Palpa, con la finalidad de reconstruir el desarrollo cultural ocurrido en la región. ${ }^{12}$ Como resultado de las mismas, hasta el momento se ha llegado a documentar un proceso cultural de más de 8000 años de historia prehispánica (Reindel 2009; Isla 2010), la cual transcurrió en un territorio bastante grande que presenta diversas condiciones geográficas y ecológicas que van desde el litoral —en la costa — hasta la puna —en la sierra_, siguiendo un eje Este-Oeste de más de 100 kilómetros de longitud (Fig. 3). Entre ambas regiones se encuentra la Yunga Desértica

10 Una variante local, conocida como Tunga Polícromo (Strong 1957) reproduce las mismas formas, motivos y colores del clásico estilo Chakipampa.

11 Originalmente el estilo Loro se relacionaba sólo con la época 1A del Horizonte Medio debido a que antecedía al estilo Chakipampa (antes Nasca 9), el cual era tradicionalmente aceptado como el estilo dominante de la época 1B (Menzel 1964). No obstante, ahora sabemos que ambos estilos no sólo son contemporáneos sino que al parecer habrían estado vigentes hasta la época 2 del HM.

12 Las investigaciones del Proyecto Nasca-Palpa han sido auspiciadas por la Fundación Suiza-Liechtenstein para Investigaciones en el Exterior (FSLA), el Ministerio Federal de Educación e Investigación de la República Federal de Alemania (BMBF) y la Comisión de Arqueología para Culturas Extraeuropeas -KAAK- del Instituto de Arqueología de Alemania (DAI). 


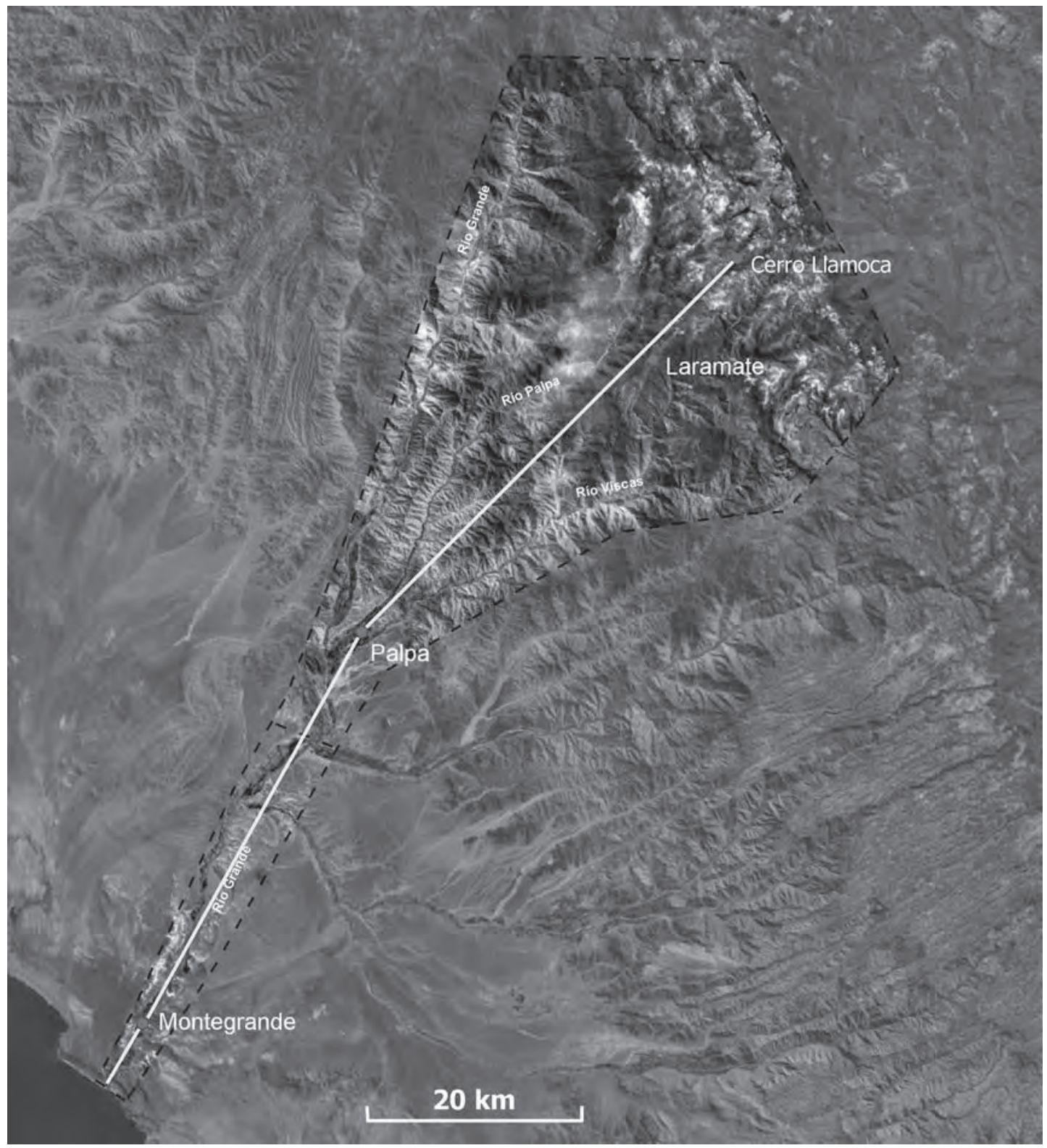

Figura 3. Imagen satelital que muestra el área de investigación del Proyecto Nasca-Palpa, el cual va desde el litoral del Océano Pacífico hasta las nacientes de los ríos Palpa y Viscas, en la cordillera occidental de los Andes.

que constituye una zona de transición caracterizada por estrechos valles y quebradas, las cuales están flanqueadas de cerros secos y sin vegetación.

En este sentido, el área de investigación del Proyecto Nasca-Palpa ocupa más de $160 \mathrm{~km}^{2}$, el cual se extiende desde la confluencia de los ríos Grande e Ingenio hasta las nacientes de los ríos Palpa y Viscas, en la vertiente occidental de los Andes.

En el marco de estas investigaciones también se han realizado diversos estudios sobre la geología, geografía y ecología de los valles de Palpa (Eitel et al. 2005; Eitel y Mächtle 2009; Mächtle y Eitel 2013), 
con los cuales se ha llegado a esbozar un panorama más completo sobre las condiciones medioambientales (paleoclima) en las que ocurrió este largo proceso cultural. Es en este contexto en el que se presentan las evidencias relacionadas con la ocupación Wari en la zona, las cuales constituyen un avance de una investigación más amplia sobre el tema.

\section{Las investigaciones en la costa}

Trabajos de prospección sistemática realizados por arqueólogos del Proyecto Nasca-Palpa entre los años 1997 y 2001 en los valles de los ríos Grande, Palpa y Viscas, en la provincia de Palpa, ${ }^{13}$ nos han permitido identificar más de 30 sitios arqueológicos en donde se han registrado diversas evidencias relacionadas con la ocupación Wari en la zona (Fig. 4). En la mayoría de los casos se trata de sitios de ocupación Nasca en donde se han identificado restos de viviendas y tumbas de filiación Wari, aunque también se han registrado algunos pocos sitios que fueron ocupados solamente durante el Horizonte Medio. Como se dijo antes, solo los sitios de Huaraco y Lambrasniyoq —localizados en la parte más alta de esta zona - presentan evidencias que indican claramente su posición dominante como centros principales de la época.

De todos los sitios en donde se han registrado evidencias Wari, solo cuatro han sido intervenidos mediante excavaciones restringidas o en área en la denominada zona de costa. ${ }^{14}$ Estos sitios son Los Molinos, Parasmarca, Huaraco y Lambrasniyoq, los cuales en diversos momentos tuvieron el rol de centros principales. Casos especiales lo constituyen los sitios de Huaraco y Parasmarca, los cuales fueron ocupados durante varias fases de la cultura Nasca pero de manera especial durante la época Nasca Tardío, tiempo en el cual se consolidaron como los centros políticos más importantes en el valle del río Grande. Esta posición dominante en el valle habría sido motivo para establecer una ocupación de igual o mayor importancia durante el Horizonte Medio. En este sentido, se debe indicar que solo el sitio de Lambrasniyoq, ubicado en la parte media-alta del valle de Viscas, fue establecido en la época 2 como un enclave principal en la región. ${ }^{15}$

A continuación se presenta un resumen de las excavaciones realizadas en cada uno de los sitios indicados, poniendo en relevancia las evidencias de la ocupación Wari registrada en cada uno de ellos.

\section{Las excavaciones en Los Molinos}

Los Molinos (PAP-93) se localiza en la margen izquierda del valle del río Grande, a $4 \mathrm{~km}$ al sudoeste de la ciudad de Palpa (Fig. 4), donde ocupa terrazas y laderas de suave inclinación que se encuentran al margen de los campos de cultivo, a $320 \mathrm{msnm}$. Justo esta parte del valle es bastante angosto pero dispone de agua superficial durante todo el año. Asimismo, cerca del sitio se encuentran grandes planicies con fértiles campos de cultivo, los cuales favorecieron el establecimiento de numerosos asentamientos prehispánicos a lo largo del tiempo.

En este contexto, Los Molinos presenta evidencias de ocupaciones de todas las épocas de desarrollo de la cultura Nasca, pero de manera especial grandes estructuras arquitectónicas de la época

13 Las investigaciones en esos años se han realizado en la parte media y media-alta de los valles de Palpa, los cuales se encuentran entre los 200 y 1200 a 1500 msnm. Entre los 750 y 2000 msnm se observa una marcada transición de costa a sierra caracterizada por un paisaje de yunga desértica.

14 Otros dos sitios donde se han realizado excavaciones son Hanaq Pacha y La Huerta, en el valle de Viscas (Fig. 4). En ambos casos se han registrado solo algunos contextos funerarios relacionados con el estilo Chakipampa.

15 Otros dos sitios de similar importancia durante este tiempo debieron ser El Manantial o La Máquina y Palpa (ubicado debajo de la actual ciudad de Palpa). 


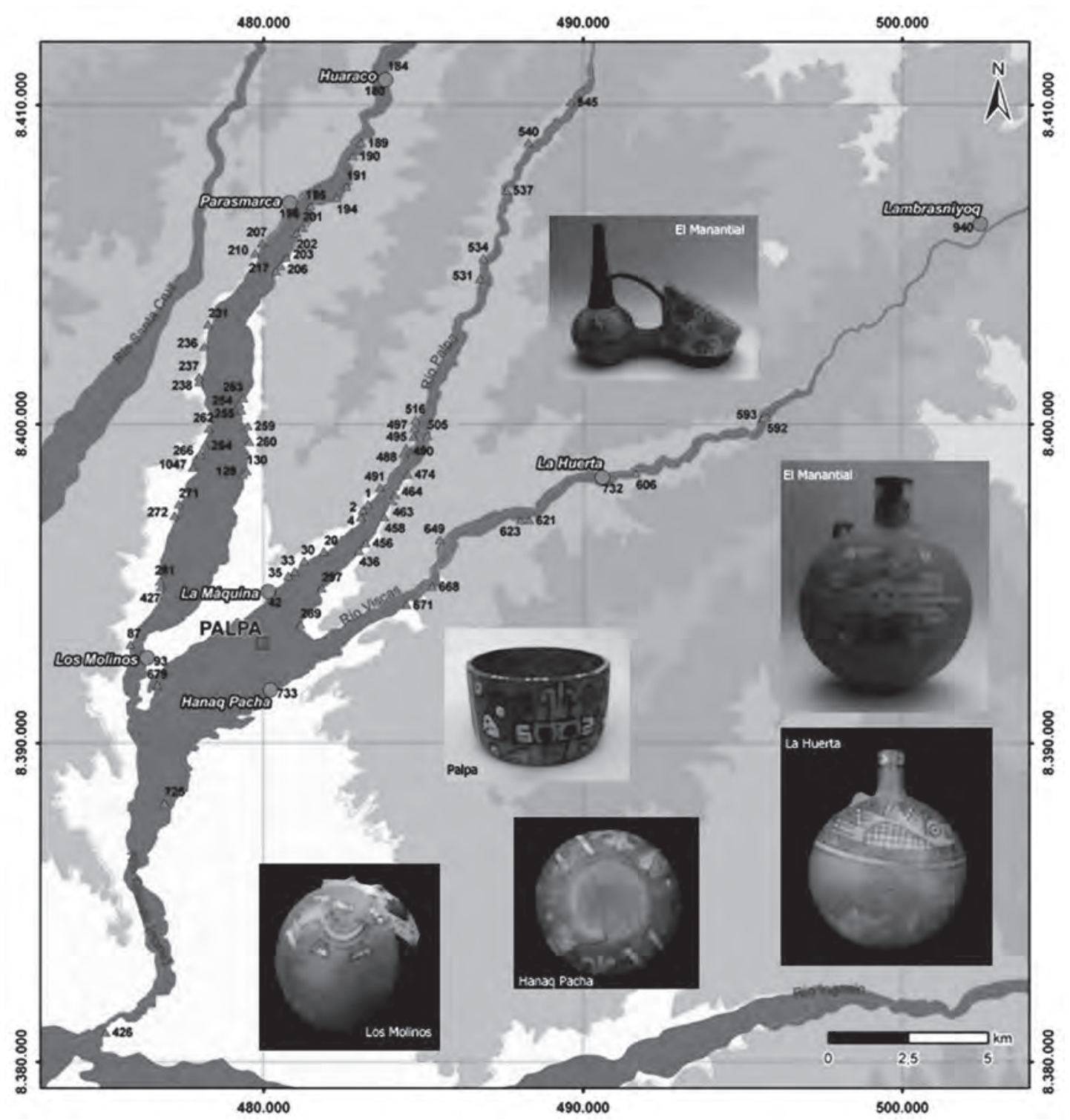

Figura 4. Mapa de la parte media de los valles de Palpa con ubicación de los sitios donde se han registrado evidencias de la ocupación Wari.

Nasca Temprano, cuando alcanzó el rango de centro político más importante de la zona (Reindel e Isla 2001). En efecto, en relación con ese tiempo, las excavaciones en área realizadas en el sitio han puesto al descubierto grandes construcciones planificadas de adobe, las cuales incluyen recintos de diferente tamaño dispuestos en plataformas escalonadas siguiendo la pendiente del terreno y conectados con escaleras y pasadizos con rampas, así como patios y otros espacios que estuvieron techados (Reindel e Isla 2001). ${ }^{16}$ Estas construcciones ocupan la mayor parte del sitio (sectores A y B). Asimismo, en el lado

16 Se trata de recintos bastante grandes en donde se han encontrado los restos de las bases de columnas y postes que indican claramente que sirvieron para sostener techos. 
Sur del sitio se encuentra un amplio sector con viviendas sencillas y cementerios pertenecientes a las épocas Nasca Temprano, Medio y Tardío (sector C), mientras que en el lado norte del sitio destaca la presencia de un grupo de geoglifos (sector D).

Por otro lado, las excavaciones realizadas en una zona intermedia entre los sectores A y C han permitido descubrir parte de un pequeño sector de viviendas, las cuales comprenden una serie de recintos de planta rectangular hechos con paredes de quincha (Fig. 5). Los materiales asociados (fragmentos de cerámica, restos vegetales, moluscos y huesos de animales) indican que estas viviendas fueron ocupadas durante la primera época del Horizonte Medio en relación con el estilo Loro. ${ }^{17}$

Asimismo, en otra parte del sitio pero en el límite oeste del sector C, las excavaciones permitieron identificar varios contextos funerarios intactos pertenecientes al Horizonte Medio, los cuales incluyen cinco entierros simples establecidos en pozos y dos tumbas en forma de "barbacoa" (Fig. 5). ${ }^{18}$ Las ofren-
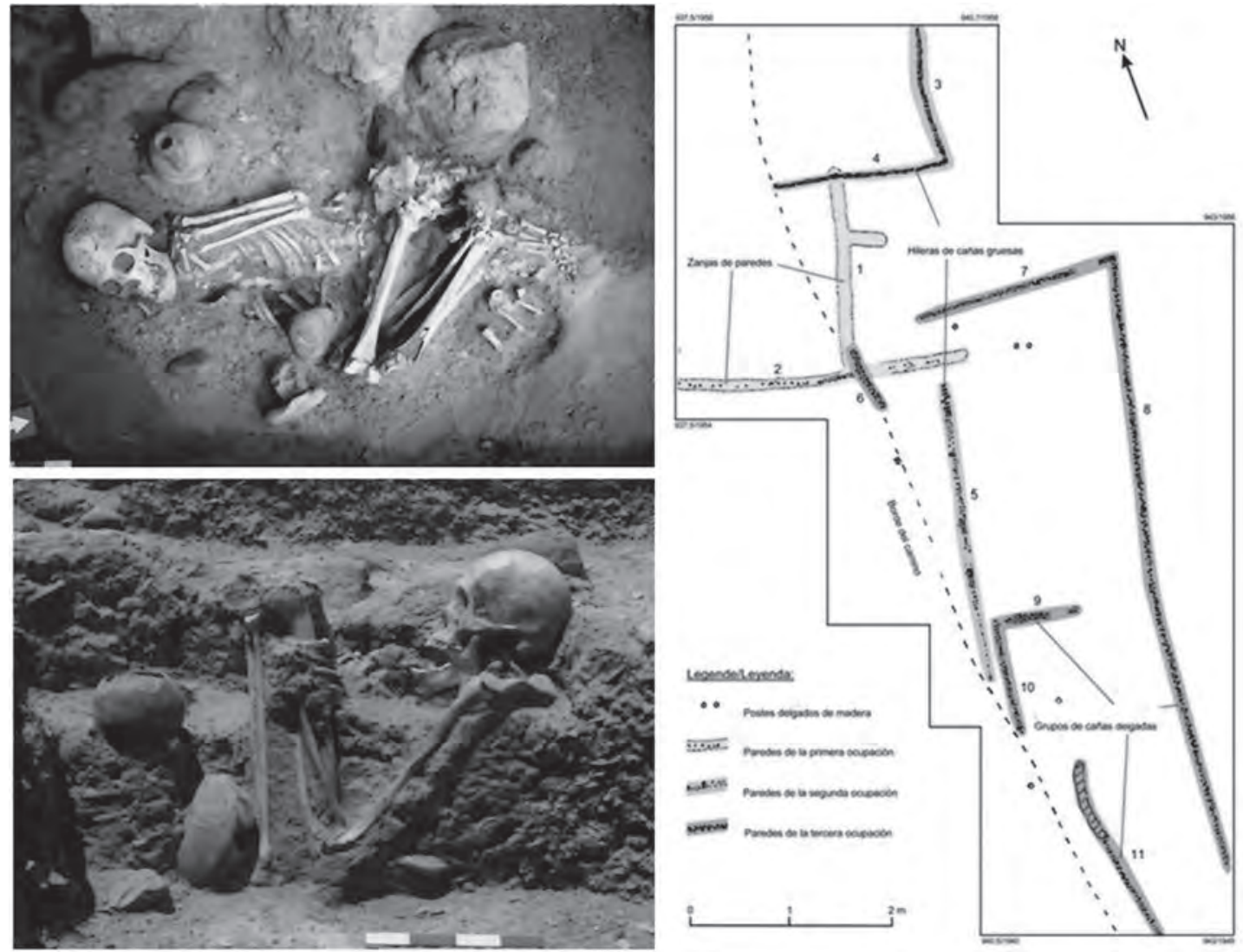

Figura 5. Contextos funerarios y viviendas de quincha registrados en el sitio de Los Molinos, en el valle de Palpa.

17 Un fechado de radiocarbono por AMS (590-665 d.C. con un sigma de calibración) obtenido de una muestra de semilla de pallar confirma que estas viviendas fueron ocupadas durante la primera época del Horizonte Medio.

18 Las tumbas en forma de barbacoa son típicas de la cultura Nasca y básicamente se caracterizan por la tener una cámara subterránea cubierta por un techo formado con palos de huarango, sobre el cual se colocaron piedras y una capa o torta de barro a modo de sello o cobertura final. 
das asociadas incluyen vasijas de cerámica pertenecientes a los estilos Loro y Chakipampa. Casi todos los contextos funerarios fueron identificados en un mismo nivel por la presencia de un sello o cobertura compuesta por una compactación de tierra, terrones y adobes. Los entierros simples corresponden a infantes que fueron depositados sin ofrendas, salvo uno correspondiente a un entierro doble compuesto por dos individuos adultos, junto a uno de los cuales se encontró un cántaro del estilo Loro.

Por otro lado, las dos tumbas en barbacoa eran mucho más grandes y cada una de ellas presenta rasgos especiales. La primera fue identificada por la presencia de dos entierros individuales de adultos que fueron colocados a la altura del techo, a modo de guardianes, en las esquinas de la matriz de forma cuadrangular (Reindel e Isla 2001: Fig. 20). Ambos entierros estaban asociados a vasijas de ofrenda del estilo Chakipampa. Asimismo, en el techo de la tumba, ${ }^{19}$ sobre el extremo de uno de los palos, se encontró el entierro de un niño que al parecer fue dejado como ofrenda y junto al cual se encontraba un vaso del estilo Tunga. Luego de retirar el techo de la tumba y el relleno interior se expuso un pozo bastante profundo, el cual en la parte inferior presenta una cámara lateral en forma de bota, cuyo acceso a la misma había sido tapada con un murete de adobes. En el interior de la cámara se encontró el esqueleto de un niño y los restos incompletos de otro niño. Asimismo, tanto en el relleno de la cámara como en el relleno del pozo se encontraron los restos incompletos y desarticulados de otros cuatro individuos. La segunda tumba, en cambio, presentaba un techo compuesto por un tendido de cinco palos de huarango, el cual cubría una cámara en forma de pozo bastante profundo que había sido totalmente rellenado con tierra y grumos de terrones. Luego de retirar el relleno, cerca del fondo de la cámara se encontró los cráneos y algunos huesos sueltos pertenecientes a cuatro individuos, así como un plato del estilo Tunga. Cabe indicar que uno de los cráneos tenía un orificio en el hueso frontal al estilo de las cabezas trofeo de la cultura Nasca.

Las evidencias documentadas en Los Molinos indican claramente que el sitio fue ocupado durante la primera época del Horizonte Medio, cuando se estableció una pequeño caserío con viviendas de quincha y un grupo de contextos funerarios, entre los que destacan entierros individuales y tumbas con entierros colectivos que constituyen una característica particular de ese tiempo (Isla 2001). ${ }^{20}$ Es posible que en otra parte del sitio o en sus alrededores haya habido viviendas más formales donde residían las personas enterradas en las tumbas más elaboradas.

\section{Las excavaciones en Parasmarca}

Parasmarca (PAP-196) se localiza en la parte media alta del valle del río Grande, donde ocupa una amplia ladera de suave inclinación que se encuentra en la margen derecha del río del mismo nombre, a $540 \mathrm{msnm}$ (Fig. 4). Se trata de un asentamiento bastante grande que fue ocupado en diferentes épocas, el cual alcanzó su mayor auge y configuración final durante la época Nasca Tardío (Nasca 7), cuando asumió el rol de centro político de primer orden en la zona (Fig. 6). ${ }^{21}$ En ese tiempo en el sitio se construyó un conjunto planificado de edificios de piedra de planta cuadrangular que incluye numerosos recintos de diferentes tamaños, alternados con patios y pasadizos, todos los cuales estaban delimitados por un muro perimétrico, alrededor del cual había un sector de viviendas rústicas de quincha, geoglifos bastante grandes y también un cementerio de la época.

19 El techo estaba compuesto por un tendido de diez palos de huarango, los cuales estaban parcialmente cubiertos por barro y terrones. El techo había colapsado debido a la humedad y al peso del relleno sobrepuesto.

20 Las excavaciones en el sector C de Los Molinos, donde se han registrado las evidencias de ocupación Wari, han sido bastante limitadas y es presumible que esa parte del sitio contenga muchas evidencias más.

21 El sitio fue ocupado desde la época Nasca Inicial (200 a.C.-50 d.C.), cuando se estableció un numeroso grupo de viviendas sencillas dispuestas en terrazas que ocupan toda la amplia ladera en el lado Sudoeste del sitio. Durante la época Nasca Medio (Nasca 4-5) se construyó un conjunto de viviendas y recintos más grandes en la parte central del sitio, así como dos grandes geoglifos de forma trapezoidal. 


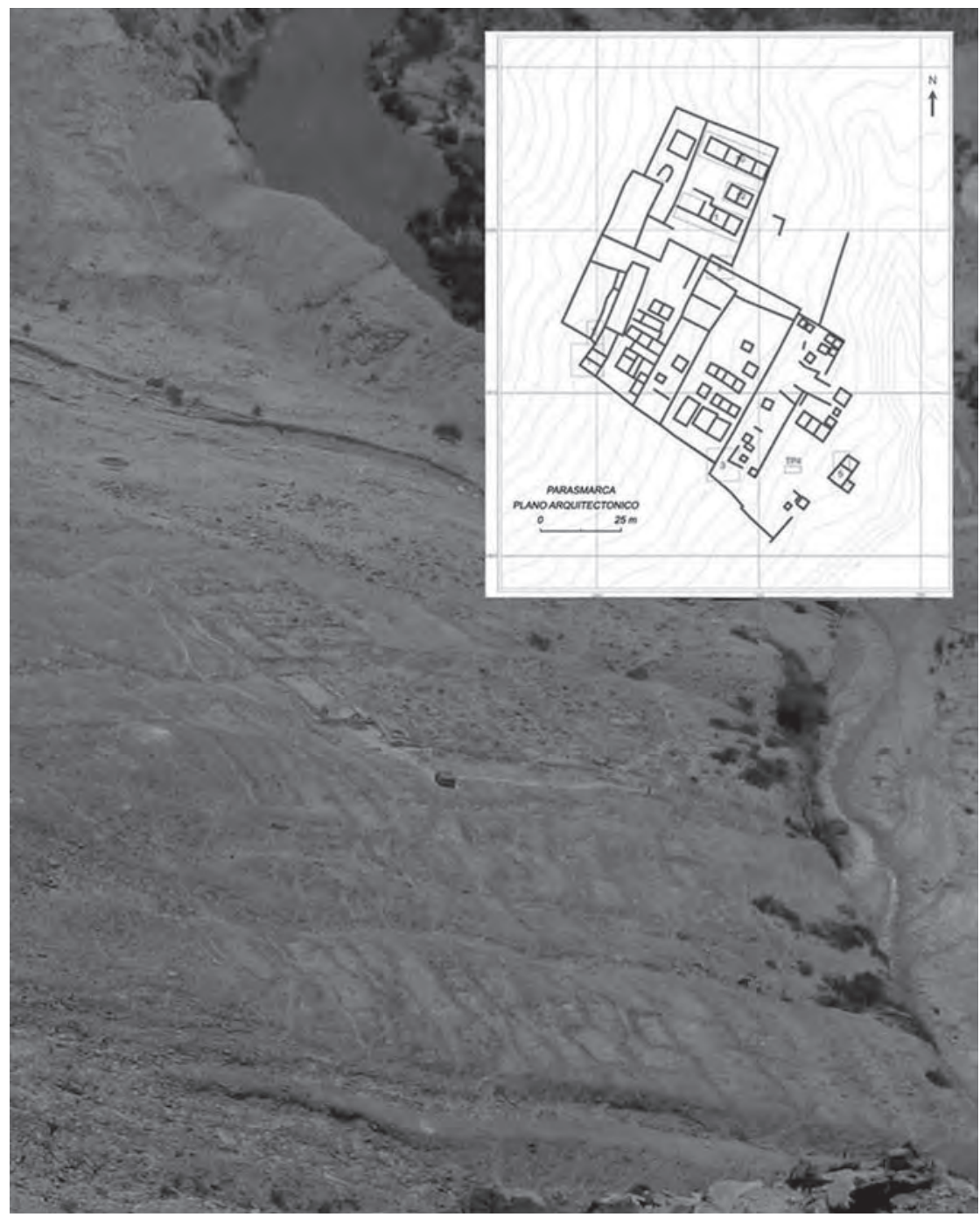

Figura 6. Foto panorámica del sitio de Parasmarca con plano topográfico y arquitectónico del conjunto principal de construcciones (sector A).

Las excavaciones en área se concentraron en el sector principal del sitio (sector A), donde además de los edificios de filiación Nasca se registraron varias tumbas saqueadas y dos tumbas intactas pertenecientes a la primera época del Horizonte Medio, relacionadas con el estilo Loro. Las tumbas fueron establecidas al interior de grandes patios de época Nasca, dispuestas en forma aislada o en grupos una al lado de la otra, formando conjuntos alargados que comparten los mismos muros de delimitación.

En general, se trata de tumbas que incluyen un pozo bastante grande y profundo excavado en el terreno natural, algunas veces en forma de bota, el cual constituye la cámara funeraria propiamente dicha, y cuya entrada estaba tapada con grandes piedras y lajas unidas con barro. En el interior había entre uno y dos individuos por tumba, rodeados de numerosas vasijas, agujas de cobre y piruros. La cámara en sí, luego de depositar al entierro y sus ofrendas, se dejaba vacía mientras que la parte superior del pozo se rellenaba hasta la superficie, en cuyo entorno se establecía un pequeño recinto de planta cuadrangular hecho con un alineamiento de piedras que delimitaba el espacio alrededor de la boca del 
pozo. Adicionalmente, alrededor de dicho recinto se construyó un muro perimétrico bajo que delimitaba un espacio libre posiblemente utilizado en rituales vinculados con el enterramiento (Fig. 7).

En algunos casos, en la parte exterior de varias tumbas se encontraron placas, cuentas y nódulos de Spondylus ubicados cerca de los muros. Tanto el pequeño recinto como el muro perimétrico formaban parte de la arquitectura funeraria de la tumba. La presencia de hoyos de postes en las esquinas indica que estas tumbas habrían estado techadas al estilo de las grandes tumbas con cámara de la fase Nasca 5 registradas en el sitio de La Muña (Isla y Reindel 2006). En base a los rasgos constructivos y los objetos asociados en las dos tumbas intactas, se puede decir que las estructuras funerarias fueron destinadas a personas de estatus medio y alto de la sociedad.

En este punto es necesario indicar que al no haberse registrado una ocupación Wari en este sector de Parasmarca, es muy posible que las tumbas arriba descritas hayan sido establecidas allí por gente que vivía en el sitio PAP-194, localizado justo al otro lado del valle. Dicho sitio ha sido casi totalmente destruido en los últimos años por la habilitación de campos de cultivo, pero hasta hace poco todavía se podían ver los restos de muros de piedra y materiales correspondientes a una importante ocupación de la época 1 del Horizonte Medio. ${ }^{22}$

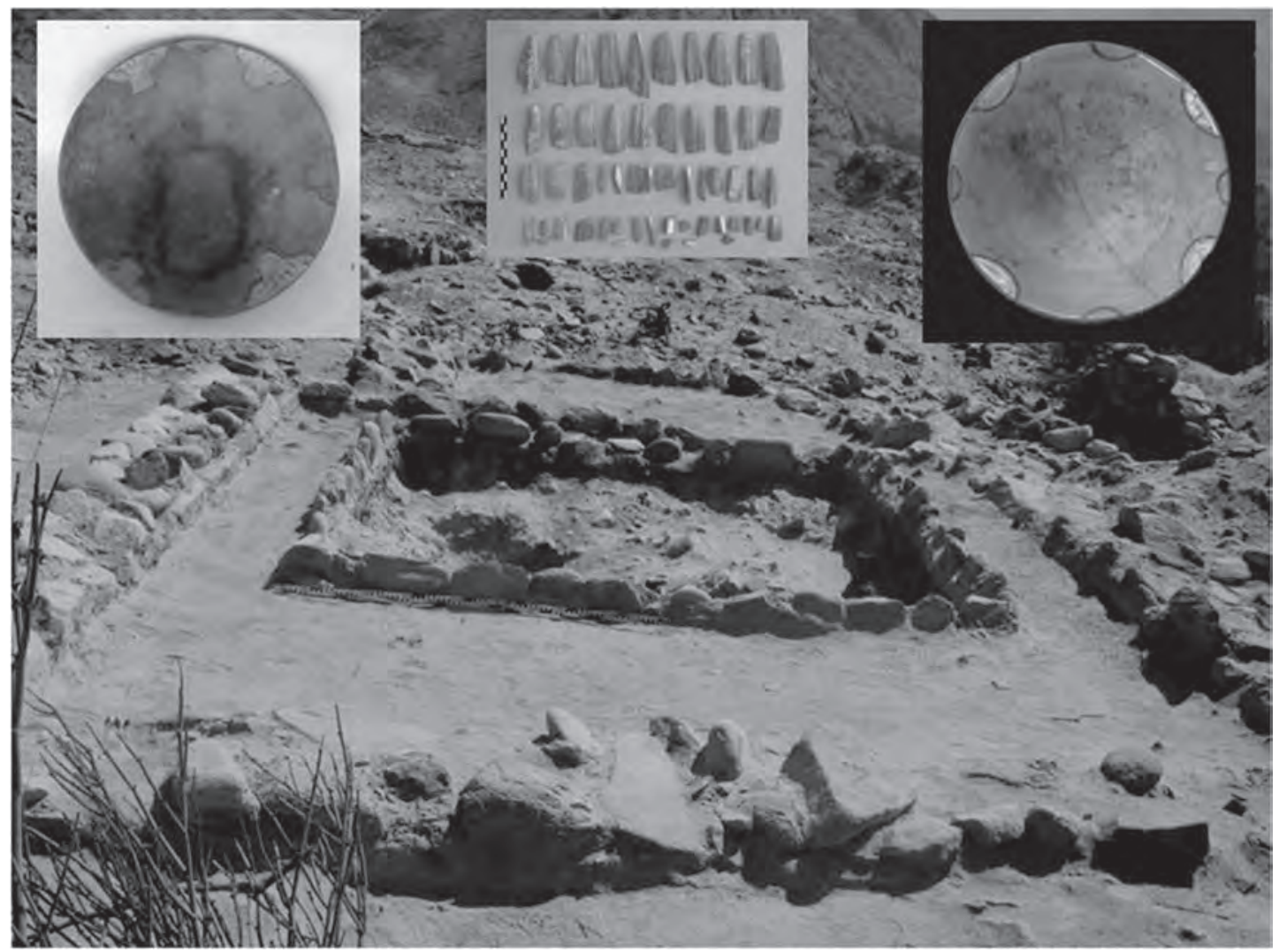

Figura 7. Vista de una de las tumbas excavadas en el sitio de Parasmarca y algunos de los objetos asociados.

22 Dos fechados de radiocarbono obtenidos de muestras procedentes de las dos tumbas intactas han dado como resultados fechas de 604-641 d.C. (para la Tumba 1 en la Unidad 5) y de 565-600 d.C. (para la Tumba 5 en la Unidad 11), ambas concordantes con la época 1 del Horizonte Medio. Ambas fechas tienen un sigma de calibración. 


\section{Las excavaciones en Huaraco}

El sitio de Huaraco (PAP-180) se localiza en la margen izquierda del valle del río Grande, en una zona intermedia entre el valle medio y alto, donde ocupa una amplia ladera de suave inclinación que se encuentra apenas arriba del borde del valle, a $600 \mathrm{msnm}$ (Fig. 4). Al igual que Parasmarca, se trata de un asentamiento bastante grande que alcanzó su mayor desarrollo durante la época Nasca Tardío (fase Nasca 7), tiempo en el cual debió tener el rol de centro político más importante en la zona. Pequeñas ocupaciones de tipo doméstico relacionadas con las épocas Nasca Inicial, Nasca Temprano y Nasca Medio también se encuentran en algunas partes y en los alrededores del sitio.

En base a las evidencias de superficie el sitio fue dividido en cuatro sectores (Fig. 8), los cuales comprenden un conjunto planificado de edificios de piedra de planta rectangular (sector A), viviendas de uso doméstico (sector B) un cementerio (sector C), todos relacionados con la ocupación Nasca 7. En el sector $C$ también hay evidencias de una ocupación doméstica de la época Nasca Temprano y varios grupos de tumbas saqueadas pertenecientes a la época 1 del Horizonte Medio. Por último, en el lado Sudeste se encuentra un pequeño cementerio Wari perteneciente a la época 2 del Horizonte Medio (sector D), en donde había grandes tumbas de piedra saqueadas.

El sector A es el más imponente del sitio, en donde se encuentra un conjunto planificado de recintos de planta cuadrangular construidas con piedras canteadas y piedras de río, los cuales se disponen en plataformas bajas delimitados por un muro perimétrico. Se trata de estructuras arquitectónicas que evidentemente corresponden a un sector residencial de uso público, las mismas que fueron reuti-

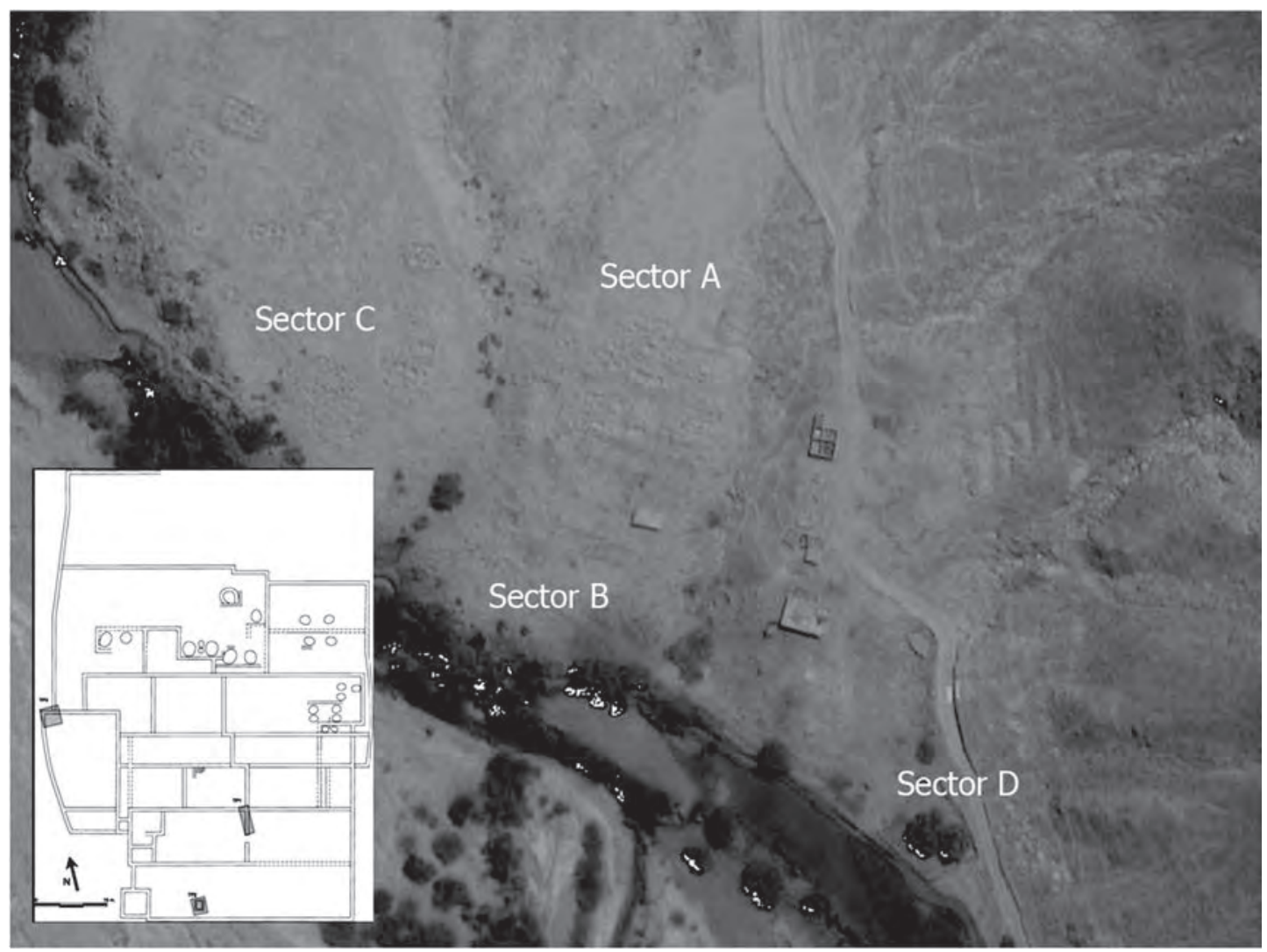

Figura 8. Foto satelital (Google) con ubicación de los diversos sectores que componen el sitio de Huaraco, donde se muestra un croquis de las construcciones del sector A. 
lizadas como cementerio al final de la época Nasca Tardío y durante la primera época del Horizonte Medio. Pequeñas excavaciones realizadas en este sector han puesto en evidencia la existencia de dos fases constructivas relacionadas con la fase Nasca 7, aunque evidentemente se necesita hacer excavaciones más grandes para poder determinar con mayor precisión los momentos de ocupación.

Por otro lado, en el sector B se encuentran recintos de piedra y quincha correspondientes a viviendas sencillas, donde predominan los desechos de actividad doméstica relacionadas con las fases Nasca 5 y Nasca 7. En tanto, el sector C comprende un cementerio saqueado de la época Nasca Tardío, pero también presenta restos dispersos de una ocupación doméstica perteneciente a la fase Nasca 3. Asimismo, en una parte del sector C se encuentran numerosas tumbas huaqueadas pertenecientes a la época 1 del Horizonte Medio, las cuales en número de dos a nueve se encuentran al interior de recintos rectangulares de piedra conformando verdaderos núcleos funerarios. ${ }^{23} \mathrm{En}$ varias de estas tumbas se han encontrado fragmentos de cerámica o partes de vasijas pertenecientes al estilo Chakipampa.

Por último, el sector D se localiza en el lado Sudeste del sitio, sobre una ladera de regular inclinación que se encuentra justo arriba del camino actual que bordea el valle. En este sector se encuentran varios pozos huaqueados correspondientes a entierros sencillos y un grupo de tumbas más elaboradas, las cuales destacan por presentar en la superficie recintos de piedra de planta rectangular que sobresalen en la superficie (Fig. 9).

Las excavaciones en el sector D nos han permitido documentar cinco tumbas saqueadas, en las cuales se observa los mismos rasgos constructivos, es decir, todas presentan una cámara funeraria de forma rectangular o cuadrangular que fue excavada en el terreno natural, la cual a su vez ha sido revestida con paredes de piedra adosadas a la pared natural. Luego de colocar el entierro (o entierros) y sus ofrendas, la cámara fue cubierta con un techo formado por gruesos palos de huarango y grandes piedras o lajas y una capa de barro, al estilo de las tumbas en forma de barbacoa de la cultura Nasca. Luego de esto, cerca de la superficie, se construyó un recinto perimétrico o antecámara de planta rectangular hecho con muros de piedra y revestidas con barro, los cuales tenían un poco más de un metro de altura. Finalmente dicho recinto fue parcialmente rellenado cubriendo totalmente el techo de la cámara funeraria. Sólo en un caso se identificó un acceso con escalones de piedra que baja a la cámara funeraria.

Aunque todas las tumbas estaban saqueadas, en dos de ellas se han encontrado entierros intactos de niños que habían sido colocados en la antecámara, ya sea en pozos hechos en el relleno dispuesto sobre los techo de la cámara funeraria (EF-4) o en una cista hecha con piedras y barro en una de las esquinas de la antecámara (EF-1). En este último caso se encontró además dos vasijas de ofrenda del estilo Soisongo. Un caso interesante a tener en cuenta es que en casi todas las tumbas se ha registrado huesos pertenecientes a más de un individuo (entre adultos, juveniles o infantes), lo que indica que en cada tumba había más de un individuo. Además de los entierros intactos y huesos humanos disturbados, en todas las tumbas se ha llegado a recuperar una regular cantidad de fragmentos de cerámica llana y pintada pertenecientes a varias vasijas, cuentas de piedras semi-preciosas, puntas de obsidiana, láminas de cobre y objetos de Spondylus. Los fragmentos de cerámica se relacionan con varios estilos Wari (Viñaque, Atarco, Soisongo, Huamanga y Qosqopa) pertenecientes a la época 2 del Horizonte Medio.

Las evidencias registradas en Huaraco indican que el sitio estuvo ocupado por un lapso de tiempo bastante prolongado que se relaciona con las épocas 1 y 2 del Horizonte Medio. Los contextos funerarios excavados corresponden a personajes de estatus medio a alto, lo que a su vez indica que el sitio

23 Estos recintos están construidos con delgados muros de piedra de doble cara, los cuales tienen en promedio un metro de altura. En algunos casos presentan divisiones interiores que al parecer estaban delimitando tumbas más importantes. En varios núcleos también se observan tumbas adicionales dispuestas en fila al exterior de los recintos. 


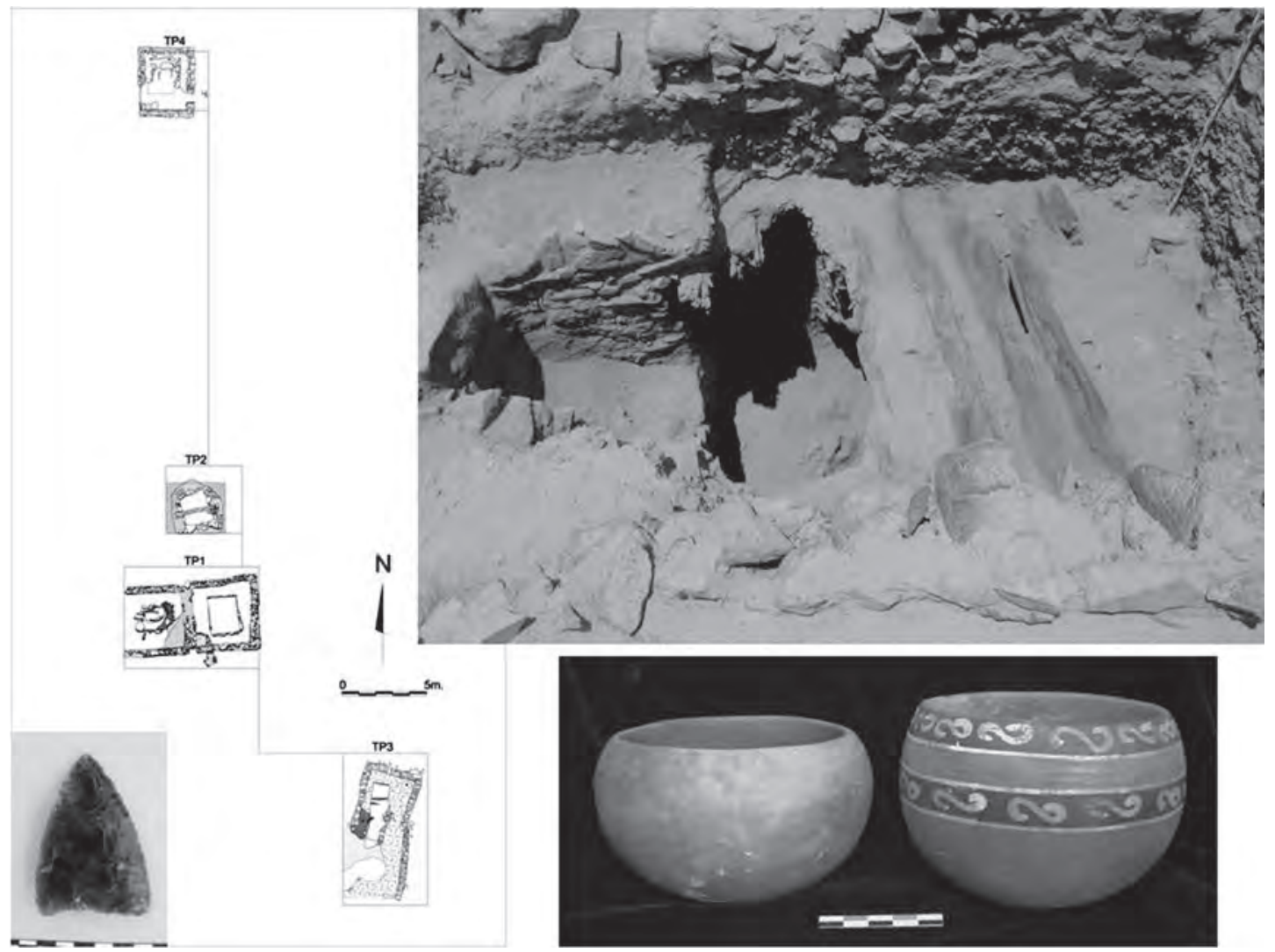

Figura 9. Plano de ubicación de las tumbas Wari en el sitio de Huaraco, con vista de una de las tumbas huaqueadas y de parte del ajuar funerario.

fue sede de una población residente muy importante cuyo lugar de asentamiento debe ser definido mediante excavaciones en área en el sector principal del sitio, donde al parecer una parte de los edificios Nasca Tardío fueron remodelados y ocupados en este tiempo.

\section{Las excavaciones en Lambrasniyoq}

El sitio de Lambrasniyoq (PAP-940) se localiza en la margen derecha del río Viscas, a 32 km de Palpa en dirección al noreste, camino hacia el distrito de Ocaña, justo en la confluencia con una amplia quebrada seca que baja hacia el valle de norte a sur. El sitio ocupa una amplia ladera de suave inclinación que se encuentra entre el borde del valle y la quebrada, justo al pie de los cerros altos que bordean la margen derecha del valle, a $1375 \mathrm{msnm}$. El sitio comprende un grupo de pequeños recintos, un edificio en forma de D, terrazas de agricultura y tumbas aisladas que en total ocupan un espacio de casi dos hectáreas.

Las construcciones se encuentran justo al pie del cerro, donde destaca un pequeño grupo de recintos de planta rectangular y terrazas de vivienda dispuestos en forma escalonada siguiendo la pendiente del terreno. Los recintos han sido hechos con muros de piedra bien elaborados que conservan hasta dos metros de altura. Todos los recintos están construidos con muros formados por una doble hilera de piedras canteadas pequeñas y medianas unidas con mortero de barro, los cuales presentan buenos paramentos e incluso en varios casos aún conservan restos del revoque o enlucido. Por otro 
lado, las terrazas han sido hechas con muros de una sola hilera de piedras más grandes, a los cuales se han adosado banquetas y muros de contención para darle una mayor estabilidad. La excavación en uno de los recintos mejor conservados puso al descubierto un único piso con escasos materiales culturales.

Asimismo, en el lado oeste del grupo de recintos se encuentra un edificio en forma de D, el cual ha sido parcialmente reconstruido en tiempos recientes por los pobladores locales y reutilizado como corral (Fig. 10). Se trata de un recinto que mide 7 x $7 \mathrm{~m}$ de lado, con un solo acceso ubicado en la parte media del muro recto, cuya construcción se realizó en base a muros anchos de doble cara que todavía conservan más de tres metros de altura. Las excavaciones en el acceso — que comprendió la parte interior y exterior del recinto- pusieron al descubierto una banqueta que estaba adosada al muro que conforma el frontis del edificio, donde todavía quedaban restos de pintura blanca, mientras que por el lado interior se expuso parte de un piso bien duro y compacto. Entre los pocos materiales recuperados en la sección excavada se encuentran fragmentos de cerámica pintada de estilo Wari, cuentas de piedras semi-preciosas y placas de spondylus.

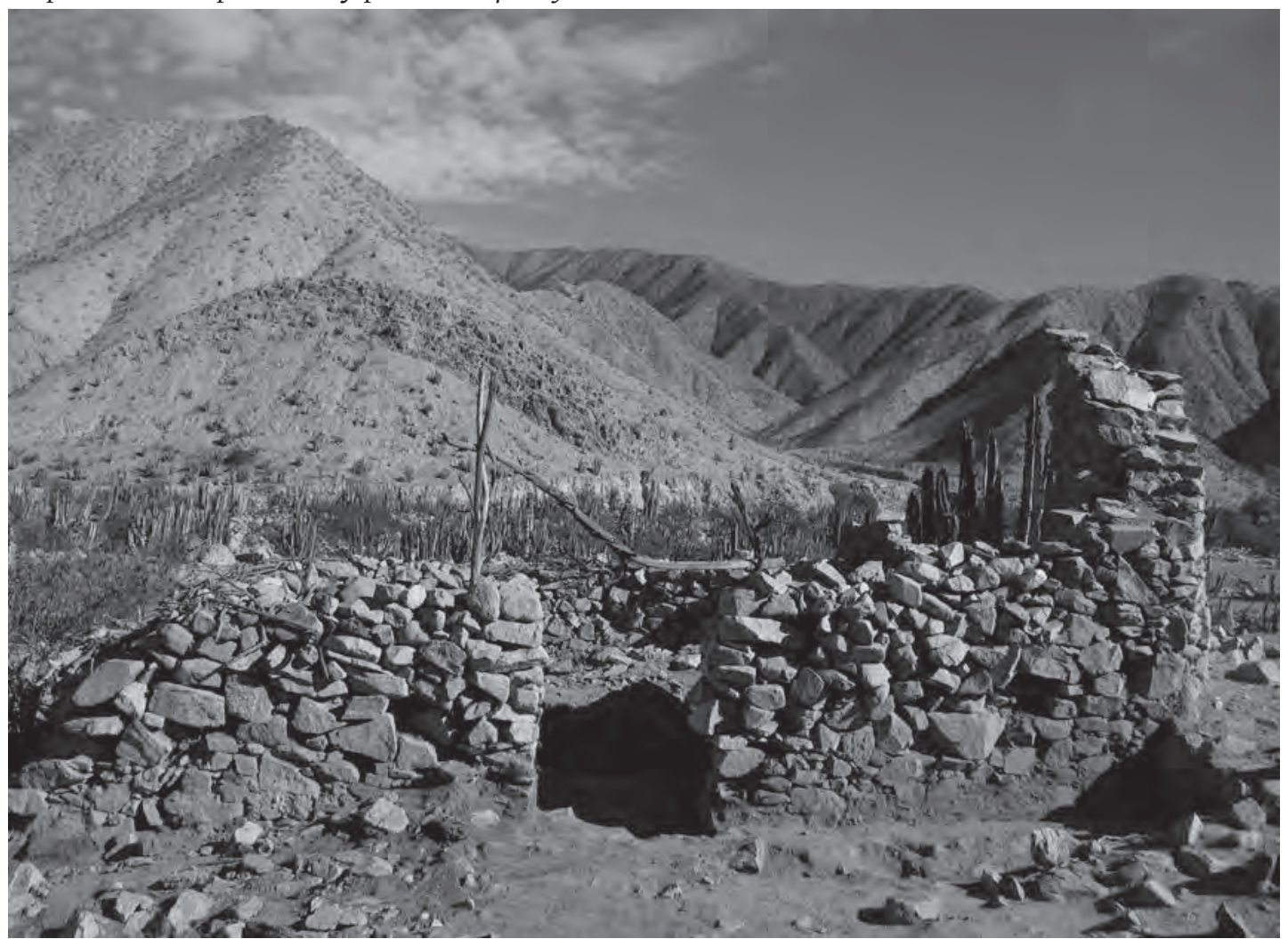

Figura 10. Vista del frontis del edificio en forma de D en el sitio de Lambrasniyoq, el cual ha sido reutilizado como corral.

Este edificio en forma de D constituye un ejemplo típico de las construcciones planificadas de carácter religioso que los Wari establecieron solo en lugares de mayor importancia (Cook 2001), siendo el primero de este tipo que se registra en esta parte de la costa sur. ${ }^{24}$ Este hecho es aún más destacable,

24 Otro edificio en forma de D pero mucho más grande se encuentra en el sitio de Mauka Llaqta, en Laramate, donde forma parte de un conjunto de construcciones que incluyen numerosos recintos de planta cuadrangular, recintos ovalados, patios, espacios abiertos y tumbas. 
si se tiene en cuenta que el sitio de Lambrasniyoq no tiene ni las dimensiones ni las construcciones existentes en otros lugares que albergan edificios de este tipo, por lo que es posible pensar que su ubicación en este lugar haya tenido un alto contenido simbólico para reafirmar la nueva ideología religiosa establecida en la región y porque además el sitio se encuentra en la ruta de uno de los caminos que bajan hacia la costa.

Por otro lado, en todo el lado oeste y sur del sitio, en una zona más plana, se encuentran varios grupos de terrazas agrícolas — amplias y bajas - que llegan casi hasta el borde del río. ${ }^{25}$ Dichas terrazas están delimitadas por muros bajos formados por un alineamiento de piedras pequeñas, medianas y grandes, las cuales son muy parecidas a las que se encuentran en la parte baja del sitio de Pataraya, en el valle de Tierras Blancas (Nasca). ${ }^{26}$ Asimismo, siempre entre los espacios libres de las terrazas agrícolas, se encuentra un grupo de cuatro tumbas huaqueadas hechas con grandes lajas y piedras de campo. Una de ellas, la más grande, tiene una forma cuadrangular (2 x 2,5 m de lado) y aún conserva parte del techo hecho en forma de falsa bóveda. Una quinta tumba — mucho más grande — se encuentra aislada en el lado sur del sitio, cerca del borde del valle, rodeado por un muro de piedras que delimitan un patio de planta ovalada (Fig. 11).

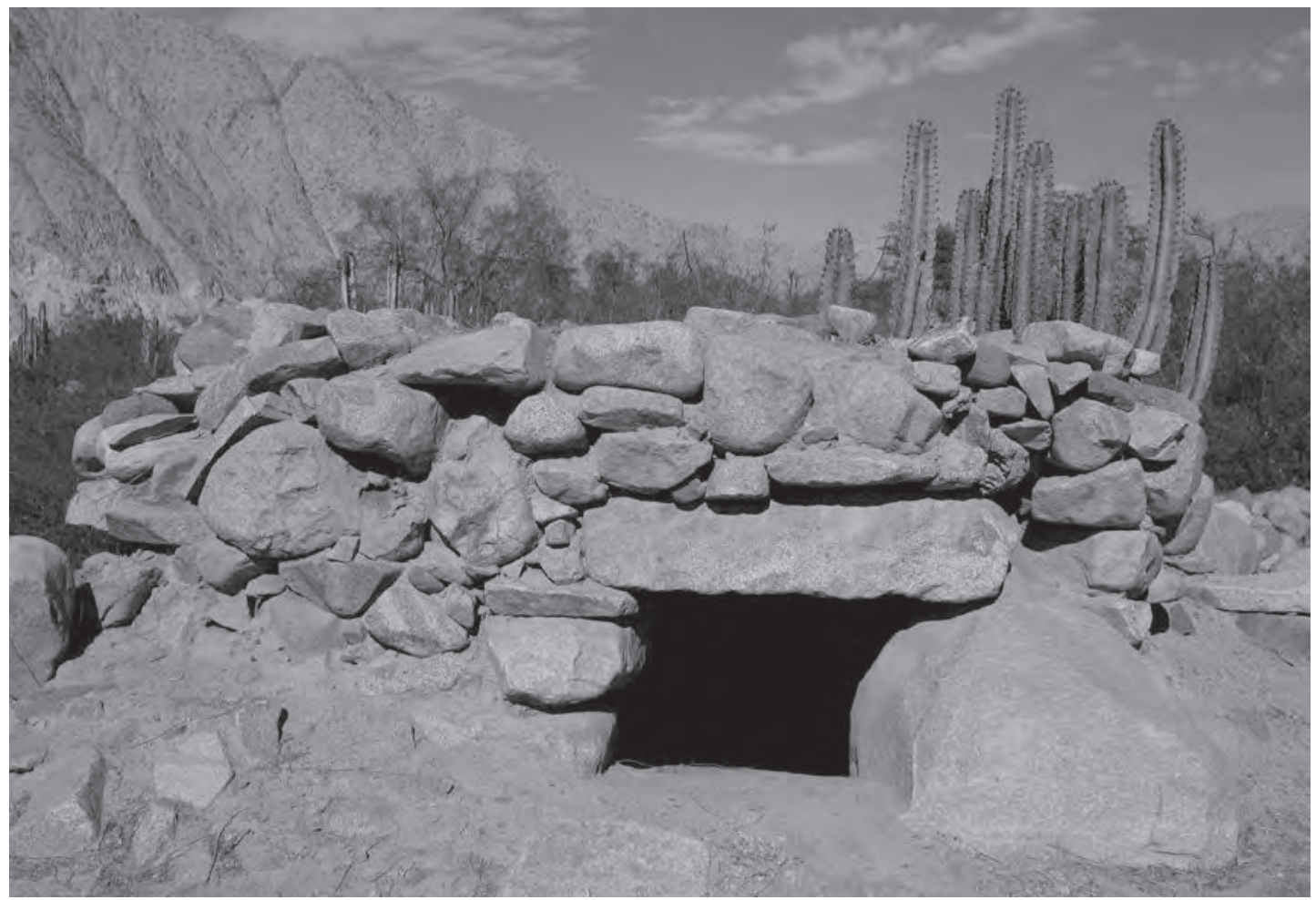

Figura 11. Primer plano de la estructura funeraria más grande registrada en el sitio, la cual conserva su estructura original aunque su interior ha sido saqueada.

25 Las terrazas que se encuentran en las partes más bajas son utilizadas hasta la actualidad por los pobladores de la zona.

26 Este sitio se localiza a $25 \mathrm{~km}$ arriba de la ciudad de Nasca y constituye un ejemplo típico de un enclave Wari con arquitectura planificada localizado en un lugar de entrada a los valles costeños (Edwards 2010). 
Tumbas de estas características son más frecuentes en la parte media alta y alta de los valles de Palpa, en una zona donde es frecuente la ocurrencia de lluvias. ${ }^{27} \mathrm{Si}$ bien todas las tumbas registradas en el sitio estaban saqueadas, los rasgos constructivos y los pocos materiales asociados indican claramente que se trata de tumbas que contenían varios individuos y que algunas de ellas estaban destinadas a personajes de alto estatus de la sociedad Wari durante la época 2 del Horizonte Medio.

\section{Las investigaciones en la sierra}

Entre los años 2006 y 2010, en el marco del Proyecto Palpa-Lucanas, los trabajos de prospección arqueológica se extendieron a la parte alta de los valles de Palpa, en la zona conocida como "las cabezadas", en la jurisdicción perteneciente a los distritos de Ocaña, Llauta y Laramate, provincia de Lucanas, Ayacucho. ${ }^{28}$ En esa zona se han identificado más de 40 sitios arqueológicos de filiación Wari, los cuales están representados por diversos tipos de asentamientos, cementerios y corrales (Fig. 12). Las evidencias arqueológicas indican que esta zona, que colinda con la provincia de Palpa, estaba fuertemente integrada con los valles costeños con los cuales compartió el mismo desarrollo cultural a lo largo del tiempo pero manteniendo rasgos propios de la sierra.

Los sitios del Horizonte Medio se encuentran en toda la zona de investigación hasta los 4400 msnm, notándose una mayor concentración entre los 2500 y 3500 m de altura, en donde ocuparon lugares más o menos planos y cerca de las zonas aptas para el cultivo. Tal como ocurrió en periodos precedentes, la mayoría de sitios del Horizonte Medio se localizan en los alrededores de los actuales poblados de Llauta, Laramate y Ocaña, en donde se encuentran grandes abanicos de fértiles campos de cultivo establecidos sobre suaves laderas, colinas bajas y numerosas quebradas por donde discurre el agua casi todo el año. Justamente en estos espacios es donde se concentra la mayor cantidad de población en la actualidad, porque constituye una zona ideal para el desarrollo de cultivos estacionales y otros de régimen anual mediante el uso de canales de riego.

Los asentamientos del Horizonte Medio están representados mayormente por pequeños caseríos, poblados menores y grandes conjuntos habitacionales que además de viviendas incluyen espacios de evidente uso público. Asimismo, también se han identificado - en la zona de tránsito entre la costa y la sierra- pequeños sitios con arquitectura formal de evidente función pública, como es el caso de Chilcapuquio (PAP-918).

La mayoría de los pequeños sitios presentan unas pocas unidades de vivienda, en algunos casos incluyen sólo dos o tres recintos y nada más, lo cual hace pensar que había poca gente viviendo en esos lugares. En este sentido, es posible pensar que la gente vivía en los sitios más grandes (tal como ocurre en la actualidad) y que sólo iban al campo de manera temporal para ocuparse de las terrazas de cultivo o del pastoreo de sus rebaños. No obstante, es importante indicar que la presencia de numerosas estructuras funerarias en los sitios pequeños estaría indicando lo contrario.

Por otro lado, los poblados menores comprenden un mayor número de construcciones domésticas, las cuales se encuentran más concentradas y alternadas con espacios abiertos. Mayormente se trata de construcciones sencillas conformadas por recintos circulares y ovalados, los cuales han sido hechos con muros de piedra de doble cara unidas con barro formando conjuntos con varios cuartos conectados a

27 Recientemente se han registrado tumbas con estas características en el sitio de La Tiza, en el valle medio de Nasca, en la margen derecha del río Aja (Conlee 2011), lo que indica que excepcionalmente también pueden encontrarse en otros sitios Wari de la zona de costa.

28 Los habitantes del lugar llaman a esta zona como "las cabezadas", aunque la misma no está ubicada en la parte más alta del macizo andino sino entre los 2500 y 3500 m de altura sobre el nivel del mar, bastante debajo del altiplano ayacuchano. En este sentido, el concepto cabezadas no se refiere a la altura absoluta del terreno sino más bien a la parte más alta que los habitantes perciben como su campo de acción. 


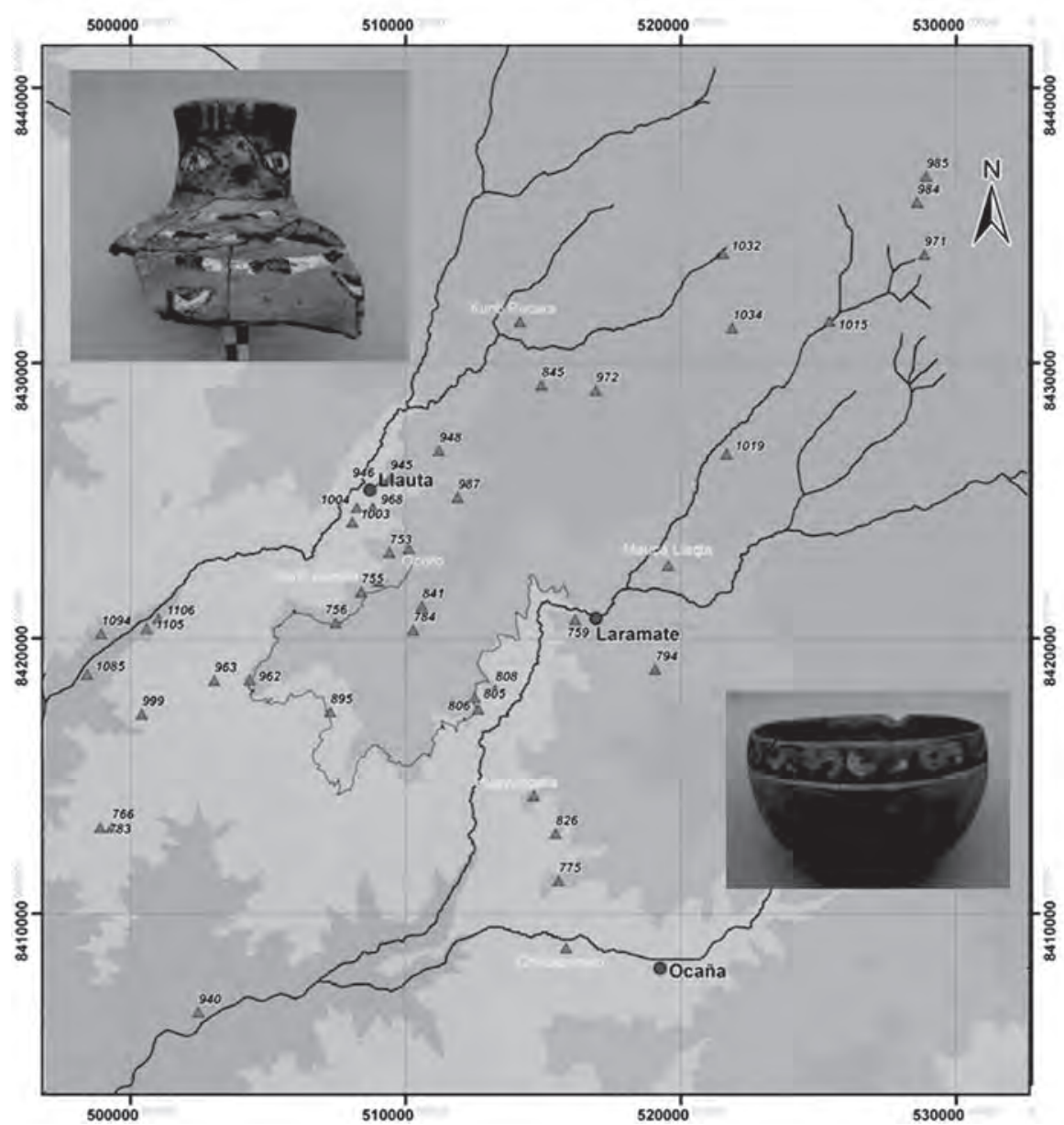

Figura 12. Mapa de la parte alta de los valles de Palpa con ubicación de los sitios Wari registrados en la zona.

través de accesos, pasadizos y patios. En este tipo de sitios también se encuentran corrales y estructuras funerarias aisladas o en grupos. Algunos de los sitios más importantes de este tipo son Occoro (PAP-751), Ayapampa (PAP-967) y Pampa Qocha (PAP-987). Ayapampa es un ejemplo típico de los asentamientos de tipo doméstico del Horizonte Medio relacionados con la agricultura, debido a que todo el espacio circundante está cubierto por amplias terrazas agrícolas que siguen la topografía natural del terreno. ${ }^{29}$ Por otro lado, Occoro constituye un ejemplo típico de los asentamientos de tipo doméstico relacionados con el pastoreo, ya que el sitio se encuentra alejado de los campos de cultivo y cuenta con varios grupos de corrales que ocupan las colinas de la parte central y Noroeste del sitio.

Los grandes poblados o conjuntos habitacionales del Horizonte Medio están representados por sitios como Mauka LLaqta (PAP-780) y Huayuncalla (PAP-814), en donde se encuentran sectores con un numeroso grupo de viviendas de planta circular o cuadrangular distribuidos en grupos alternados con patios y espacios abiertos. Asimismo, también se encuentran construcciones mejor elaboradas y

29 Diversos conjuntos de terrazas agrícolas en la zona se encuentran desde mucho antes en relación con sitios Paracas y Nasca. 
de planta rectangular que claramente fueron destinadas a cumplir funciones distintas a la doméstica. Las construcciones en estos sitios muestran un mejor acabado y evidentemente están distribuidos en diferentes sectores. En el sitio de Mauka LLaqta además se encuentra un gran edificio en forma de D, ejemplo típico de las estructuras religiosas más importantes Wari. En Huayuncalla también hay dos edificios de planta casi circular que fueron establecidos al interior de un recinto rectangular más grande, los cuales al parecer cumplieron funciones ceremoniales vinculadas con el ritual mortuorio. En este tipo de sitios también se encuentran varias estructuras funerarias o kuntis, las cuales se disponen en grupos y en forma aislada en los límites de ambos poblados.

Un cuarto tipo de asentamientos Wari está representado por pequeños sitios que presentan unos pocos edificios o construcciones formales de planta rectangular, los cuales al parecer fueron destinados a cumplir funciones de carácter público. Estos sitios se han identificado en un nivel más bajo, entre los 1350 y los $2500 \mathrm{~m}$ de altitud, en una zona de tránsito entre la costa y la sierra, donde los valles son angostos, con pocos campos de cultivo y donde el paisaje presenta una notable aridez. Dos sitios (PAP-1094 y PAP-1105) se localizan en el valle de Palpa, los cuales todavía conservan sólidas construcciones de piedra que comprenden recintos de planta rectangular de diferentes tamaños conectados entre sí, los cuales incluyen un patio o espacio abierto y otras pequeñas construcciones rectangulares asociadas. ${ }^{30}$ Otros dos sitios (PAP-918 y PAP-940) se localizan en el valle de Ocaña-Viscas, en donde las excavaciones han puesto en evidencia que se trata de sitios de carácter público pertenecientes a la época 2 del Horizonte Medio. ${ }^{31}$ En ambos casos se trata de sitios pequeños que debieron estar ocupados por una pequeña elite de la población y un grupo de servicio.

En cuanto a los sitios ubicados en la zona de mayor altura, a diferencia de los sitios Paracas y Nasca, los sitios del Horizonte Medio son más frecuentes posiblemente debido a la abundancia de vegetación tanto en la zona Suni como en la zona Puna. En este contexto, los sitios del Horizonte Medio se encuentran alrededor y encima del cerro Llamoca o Yana Orqo, en la parte más alta de la zona de investigación, pero también hay sitios de esta época en las pampas que se encuentran entre los ríos Palmadera y Atocata, afluentes de los ríos Llauta y Laramate. ${ }^{32}$ Los sitios localizados cerca del altiplano corresponden principalmente a sitios pastoriles en los que predominan los corrales asociados a unos pocos recintos de vivienda. A diferencia de sitios pastoriles de otras épocas, en los sitios del Horizonte Medio a veces se encuentran corrales de planta más o menos rectangular.

Otro rasgo característico de los sitios del Horizonte Medio es la presencia de grandes tumbas o estructuras funerarias conocidas como kunti, ${ }^{33}$ las cuales se disponen en grupos cerca de las viviendas, un poco alejadas de ellas o en forma aislada lejos de los poblados y cerca de las terrazas de cultivo. Se trata de tumbas cuya construcción usualmente sobresale al nivel de la superficie, son de planta circular, ovalada o cuadrangular, miden en promedio 2 x 3 a 3 x 4 m de lado y tienen entre 1,5 a 2 m de altura, mientras que la altura interior varía entre 1 y 1,5 m. Los muros de estas tumbas están hechos con grandes piedras o incluso bloques de forma paralepípeda pero sin trabajar, rematados con techos en forma de falsa bóveda construidos con grandes lajas. En algunos casos los techos están conformados por solo un gran bloque de piedra. En general estas tumbas tienen un acceso bajo en uno de sus lados, con una piedra grande sirviendo como dintel. Asimismo, algunas tumbas conservan un pequeño patio alrededor delimitado por un muro o alineamiento de piedras que se encuentra a la entrada

30 Futuras excavaciones en estos dos sitios permitirán conocer con mayor detalle las características arquitectónicas, el tiempo de ocupación y la función que tuvieron.

31 El sitio PAP-940 se refiere a Lambrasniyoq, el cual se encuentra en una zona intermedia entre la costa y la sierra, y que ya fue ya fue descrito en la sección correspondiente a la costa.

32 Estos son los nombres con los que se denominan a los ríos de Palpa y Viscas respectivamente en la parte alta de la zona de investigación.

33 Con este nombre se conoce a las estructuras funerarias del Horizonte Medio en la zona. 
o circundando toda la estructura funeraria. Según la cantidad de restos óseos humanos observados al interior de algunos kuntis, se trata de tumbas que contenían entierros colectivos. ${ }^{34}$

Este tipo de estructura funeraria se encuentra en toda la zona de investigación pero con mayor frecuencia en los sitios que se encuentran en la zona comprendida entre los ríos Llauta y Laramate. Los kuntis localizados en sitios de mayor altura se han registrado en el sitio PAP-985, el cual se encuentra a $4283 \mathrm{msnm}$. Se trata de un sitio de pastores que mayormente presenta corrales y por tanto es diferente a los sitios localizados más abajo, sin embargo las estructuras funerarias son muy parecidas y por tanto no sorprende encontrar allí materiales del Horizonte Medio.

Por otro lado, si bien se trata de un rasgo arqueológico presente en otros períodos de tiempo, ${ }^{35}$ las terrazas agrícolas del Horizonte Medio (al menos las que se encuentran cerca de los sitios más representativos) se distinguen de aquellas de otras épocas porque son más bajas y amplias, lo cual seguramente obedece a su localización en terrenos de menor pendiente. Por la misma razón los muros de contención están hechos mayormente con solo una o dos hileras de piedras que siguen la suave pendiente del terreno. Asimismo, la mayoría de terrazas están divididas por muros que posiblemente servían para delimitar tipos de cultivo o posesiones familiares. En algunos sitios (p.e. PAP-997) los espacios delimitados presentan entradas marcadas por dos piedras más grandes que aquellos que conforman el muro de delimitación.

Finalmente, en este punto también es importante indicar que dos caminos de larga distancia atraviesan la zona de investigación conectando la parte baja y media de los valles de Palpa con la zona de las cabezadas y por ende con el altiplano ayacuchano, es decir, comunicando a la costa con la sierra. Uno de ellos es más corto y se dirige desde el altiplano hacia el valle de Viscas mientras que el otro es más largo y se dirige hacia el valle de Palpa. En ambos casos se observan tramos bien conservados pero también hay partes donde se pierden debido a que no presentan ningún rasgo constructivo como los caminos Inka.

El camino más corto, el que baja hacia el valle de Viscas, presenta un tramo bastante bien conservado entre Laramate y Colca Grande (cerca de la confluencia de los ríos Laramate y Ocaña), el cual es utilizado hasta la actualidad por los pobladores de la zona. El camino más largo, el que baja hacia el valle de Palpa, ha sido bien identificado entre los caseríos de Armaycancha y Tambo, cubriendo un tramo de unos $37 \mathrm{~km}$ de largo y casi 2,000 metros de desnivel. El camino tiene varias desviaciones pero hay uno más definido que baja hacia el valle de Viscas, justo a la altura de Lambrasniyoq (PAP-940). Como ya se dijo, este sitio data de la época 2 del Horizonte Medio y es muy probable que los Wari lo hayan utilizado como punto de paso en sus largos recorridos entre la costa y la sierra.

\section{Excavaciones en sitios de la sierra}

En los últimos años, como parte de las investigaciones del Proyecto Palpa-Lucanas, se han realizado excavaciones restringidas y en área en tres diferentes sitios del Horizonte Medio. Estos sitios son Occoro (PAP-751), Chilcapuquio (PAP-918) y Huayuncalla (PAP-814), en cada uno de los cuales se ha llegado a registrar y documentar importantes evidencias que nos permiten conocer mejor las características que tuvo la ocupación Wari en la zona. El sitio de Lambrasniyoq se encuentra en la Yunga Desértica, en la zona de transición entre la costa y la sierra.

34 La mayoría de estas estructuras funerarias han sido saqueadas en años pasados dejando expuestos los restos humanos. No obstante, en los sitios de Occoro y Huayuncalla hemos llegado a descubrir algunas tumbas intactas.

35 Los estudios realizados nos han permitido registrar grandes complejos de terrazas agrícolas en la zona, las más antiguas de las cuales se relacionan con la ocupación Paracas Tardío. Uno de los sitios más representativos de ese tiempo Cutamalla (PAP-767). 


\section{Las excavaciones en Occoro}

El sitio de Occoro (PAP-751) se localiza en la margen izquierda del Río Llauta, casi a mitad de camino entre los poblados de Llauta y Laramate, donde ocupa una amplia llanura inclinada que se encuentra alternada con colinas bajas, a una altura de $3330 \mathrm{msnm}$ (Fig. 12). En base a los rasgos arqueológicos de superficie, el sitio ha sido dividido en cuatro sectores que incluyen un pequeño sector de viviendas, otro con grandes recintos de forma irregular de función no definida, varias estructuras funerarias y dos grupos de corrales.

El sector A ocupa el lado Sudeste del sitio y comprende un grupo de viviendas aglutinadas de planta ovalada, circular y cuadrangular, así como cinco estructuras funerarias. El sector B se encuentra inmediatamente al Oeste del sector A, donde hay varios grandes recintos que al parecer corresponden a corrales, cerca de los cuales se encuentran pequeños recintos de planta circular. El sector C se encuentra al Noroeste de A y B, ocupando la colina más grande, cuya cima casi plana está rodeada por un muro perimétrico al interior del cual se encuentran algunos recintos de planta circular y otros espacios más grandes a modo de patios. Finalmente, el sector D ocupa el lado Noreste del sitio, en donde se observan los restos de grandes recintos parecidos a los del sector B con pequeñas estructuras asociadas. Cerca de este sector también hay otras cuatro pequeñas tumbas aisladas. ${ }^{36}$

Los rasgos arquitectónicos y la organización de los espacios nos indican que el sitio corresponde a un poblado rural que según los datos obtenidos en dos excavaciones de prueba fue ocupado solamente durante la época 2 del Horizonte Medio. Los muros que conforman los recintos están hechos con una doble hilera de piedras unidas con barro y por lo general están asociados a un solo piso o nivel de uso. Por otro lado, entre las varias estructuras funerarias registradas en el sitio (Fig. 13a), las cuales fueron saqueadas en años pasados, había una que estaba intacta y en su interior se registró un enterramiento múltiple compuesto por 10 individuos adultos cuyos restos incompletos habían sido colocados sin mayor orden al fondo de la cámara (Fig. 13b). Al menos seis cráneos presentan deformación de tipo tubular. Junto con los huesos se encontró una punta de obsidiana, un plato llano y parte de una pequeña vasija en forma de cantimplora del estilo Chakipampa.

\section{Las excavaciones en Chilcapuquio}

El sitio de Chilcapuquio (PAP-918) se localiza en la margen izquierda del río Ocaña, sobre una loma alargada de suave inclinación que se encuentra arriba del borde del valle, a $5 \mathrm{~km}$ al oeste del poblado de Ocaña y a $2550 \mathrm{msnm}$ (Fig. 12). Se trata de un pequeño asentamiento bien estructurado, cuyas construcciones se dividen en dos grupos de recintos que ocupan las partes más planas de la lomada (Fig. 14).

A pesar que el sitio ha sido parcialmente destruido, ${ }^{37}$ todavía es posible observar los cimientos de los muros que conforman dos conjuntos de recintos de planta rectangular o cuadrangular, los cuales incluyen pequeños recintos alargados a modo de galerías que se disponen alrededor de patios centrales o recintos más grandes que se disponen uno al lado del otro. En todos los casos los muros están construidos con una doble hilera de piedras canteadas y relleno interior. Las excavaciones de prueba en dos pequeños recintos han permitido observar la buena conformación de los muros, los cuales presentan buenos paramentos interiores con acabados que incluyen revoque y enlucido de barro. Un piso de barro bien compactado se observa en uno de los recintos excavados.

36 En el extremo noroeste del sector $C$ se encuentra una estructura funeraria bastante grande, la cual tiene 4 metros de diámetro y ha sido construida con inmensas piedras de tipo megalítico. Dicha estructura está delimitada por un muro perimétrico de forma circular de 20 metros de diámetro, con un pequeño acceso orientado hacia el Noreste.

37 Lamentablemente la mayor parte de las construcciones del sitio han sido desmontadas o destruidas por los pobladores de la zona para la construcción de corrales actuales. 


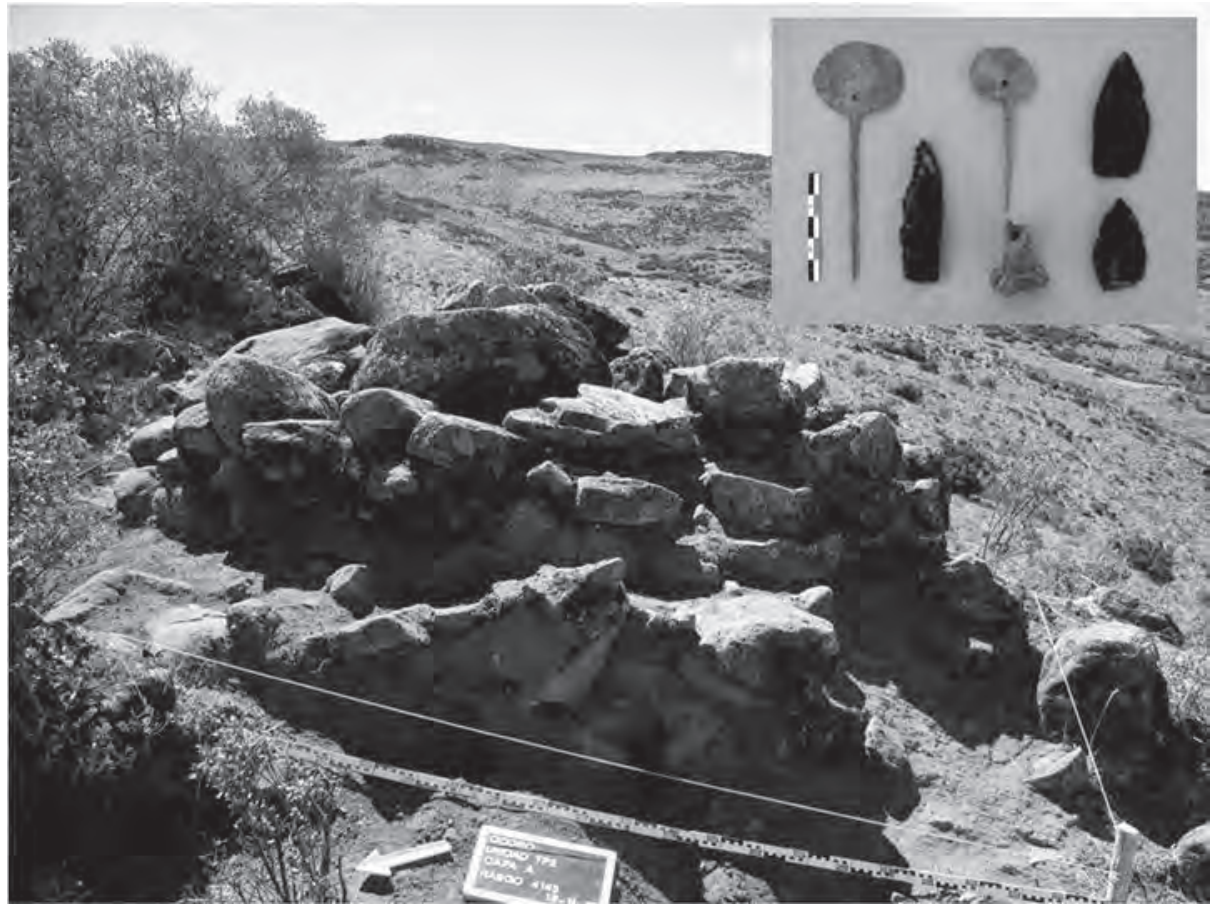

Figura 13a. Tumba intacta excavada en Occoro, la cual ha sido construida en base a grandes lajas paradas y piedras apiladas conformando un techo en forma de falsa bóveda. También se muestran los objetos hallados en el interior.

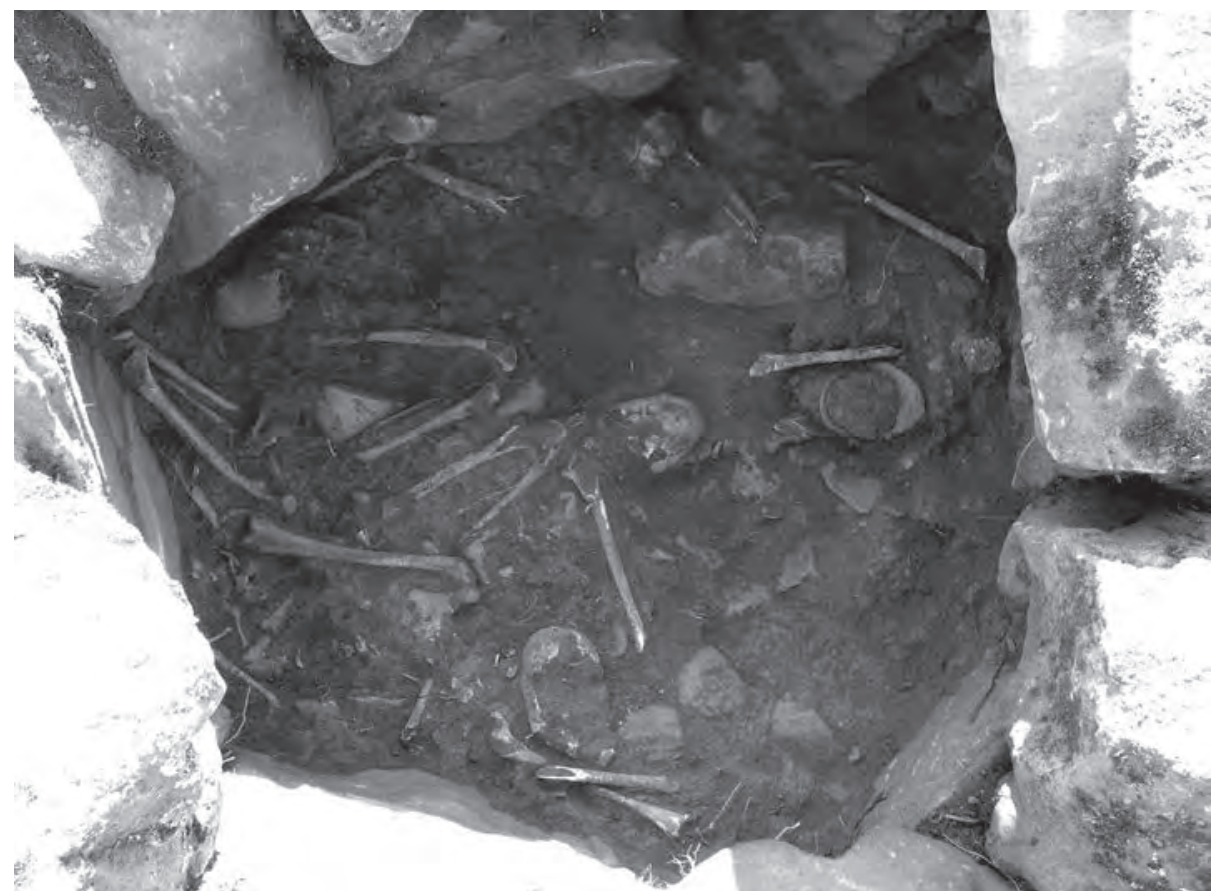

Figura 13b. Primer plano del interior de la tumba (cámara funeraria) donde se pueden ver los restos óseos incompletos de 10 individuos adultos. 

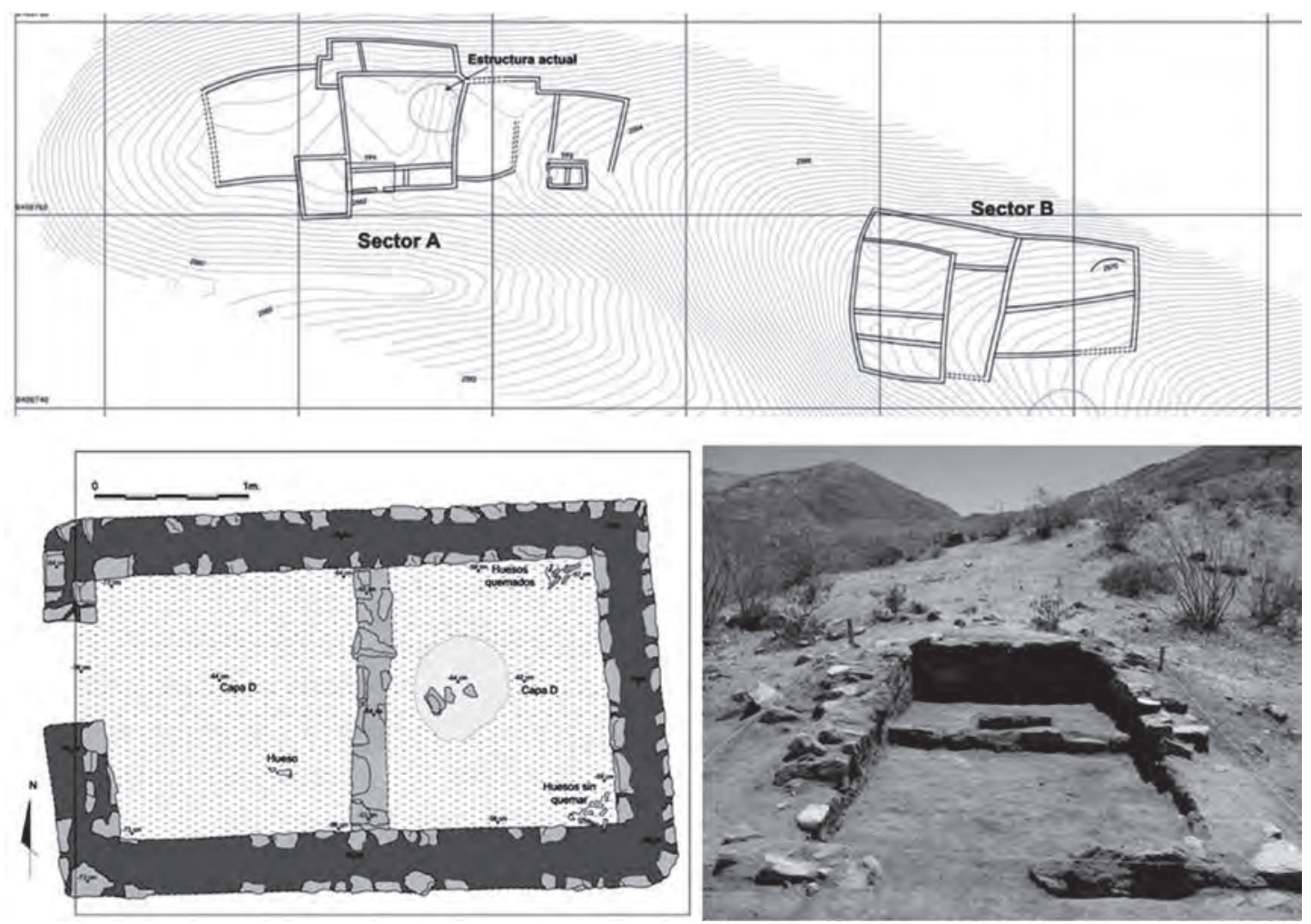

Figura 14. Plano del sitio de Chilcapuquio con vista de uno de los recintos excavados.

Según los rasgos arquitectónicos y los materiales asociados, las construcciones de este sitio datan de la época 2 del Horizonte Medio. Es claro que se trata de estructuras arquitectónicas de carácter público, en las cuales se puede reconocer fácilmente el sello o el estilo de las construcciones más importantes de la cultura Wari. Sitios de este tipo son muy pocos y por tanto es posible que en él se hayan desarrollado actividades de carácter administrativo, las cuales de algún modo debieron estar relacionadas con las actividades llevadas a cabo en Lambrasniyoq, otro sitio del mismo tipo establecido en el mismo valle pero unos kilómetros más abajo, siguiendo el camino a la costa.

\section{Las excavaciones en Huayuncalla}

Huayuncalla es el nombre de un asentamiento bastante grande que ocupa toda la cima y laderas circundantes de un cerro alargado que se localiza en el sector del mismo nombre, a unos $15 \mathrm{~km}$ al sur del poblado de Laramate, a $3100 \mathrm{msnm}$ (Fig. 12). Superficialmente en el sitio se observan una serie de construcciones de piedra de planta ovalada, circular y cuadrangular pertenecientes a una importante ocupación Wari, las cuales en algunas partes se sobrepone a ocupaciones precedentes relacionadas con la época Paracas Tardío, Nasca Inicial, Nasca Medio y Nasca Tardío.

En base a los rasgos y evidencias de superficie, el sitio presenta cuatro componentes arquitectónicos: numerosos recintos de vivienda o habitación, construcciones rectangulares relacionadas con áreas de vivienda y trabajo, recintos de posible uso público y ceremonial, y estructuras funerarias (Fig. 15). Las construcciones arqueológicas son poco visibles debido a la presencia de arbustos y porque muchas de ellas han sido desmontadas por la construcción de corrales actuales (especialmente en la parte alta del sitio), mientras que las estructuras funerarias han sido saqueadas en años pasados. 


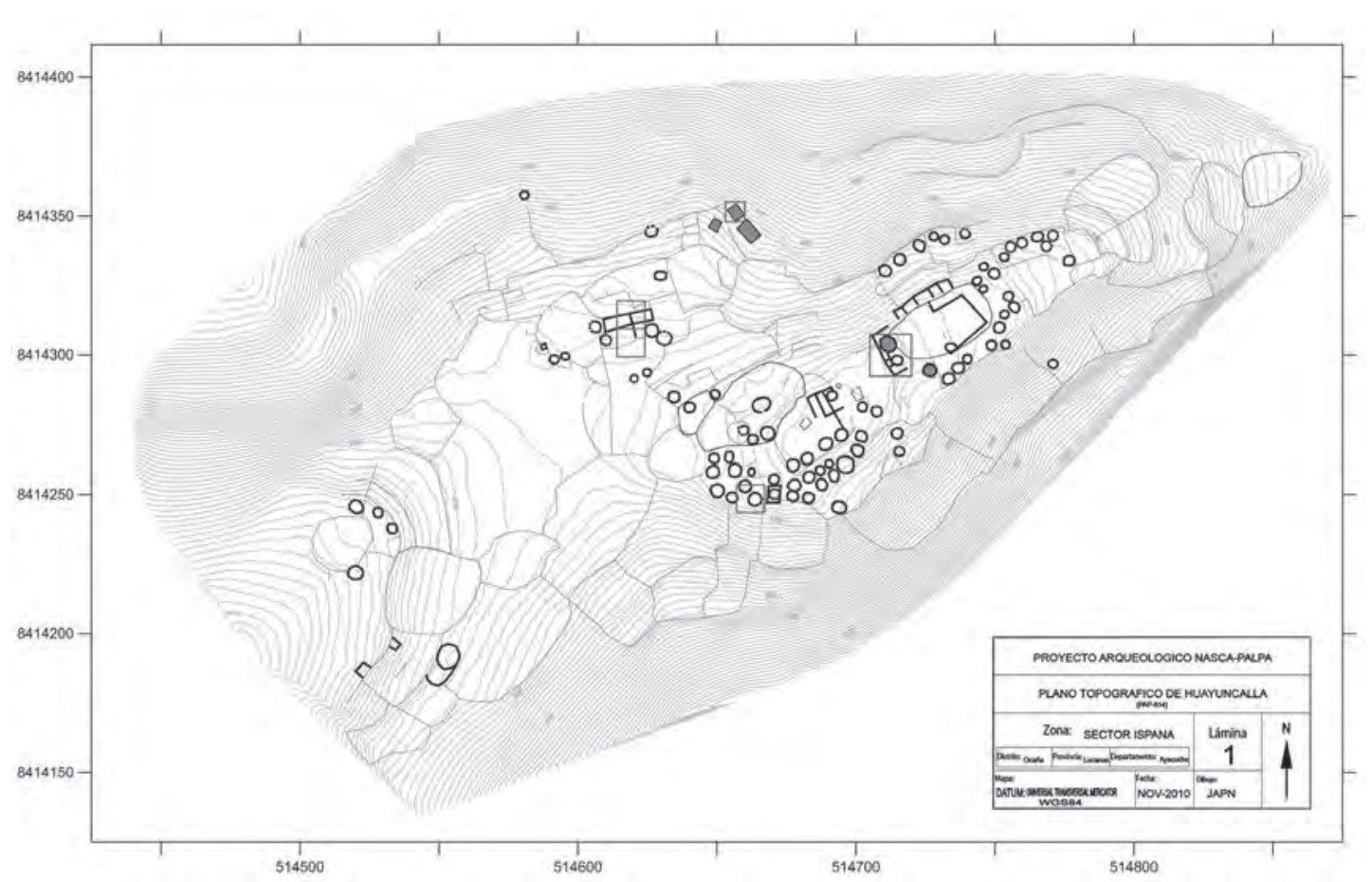

Figura 15. Plano topográfico y arquitectónico del sitio de Huayuncalla, el cual se localiza sobre una colina alargada.

Las excavaciones en Huayuncalla han comprendido excavaciones en área realizadas en cada uno de los sectores antes indicados. De este modo, una unidad de excavación se estableció en el sector de viviendas, en el lado sur del sitio, en donde se encuentran una serie de recintos de planta ovalada y circular conectados con patios y corredores intermedios. Se trata de construcciones sencillas hechas en base a muros bajos formados por una doble hilera de piedras y simples apisonados. Los restos hallados indican que en estos espacios se llevaban a cabo actividades de cocina y uso doméstico durante la época 2 del Horizonte Medio.

En el sector donde predominan las construcciones cuadrangulares se ha establecido otra unidad de excavación, en donde se ha llegado a documentar una serie de recintos de planta rectangular que fueron ocupados en dos momentos sucesivos durante la época 2 del Horizonte Medio. Se trata de recintos grandes y de diferente tamaño, los cuales fueron construidos con muros formados por una doble hilera de piedras unidas con barro, los cuales se distribuyen en plataformas bajas siguiendo la pendiente del terreno. Los recintos tienen simples apisonados en relación a los cuales -y en los rellenos de base- se ha encontrado una gran cantidad de fragmentos de cerámica y huesos de animales, así como batanes, objetos de cobre (agujas, tupus, etc.), artefactos para la producción de cerámica, puntas de obsidiana, etc. Entre los cientos de fragmentos de cerámica llana había algunos fragmentos pintados de los estilos Chakipampa, Soisongo, Qoscopa, Atarco y Viñaque. Asimismo, en los diferentes recintos se han encontrado varios entierros - pertenecientes a infantes y adultos- que fueron dispuestos en ollas y en pozos excavados en el relleno o en la capa natural. Se trata de entierros sencillos $\mathrm{y}$ en ninguno de ellos hubo ofrendas asociadas.

En este punto es importante indicar que en esta parte del sitio, debajo de las construcciones del Horizonte Medio, se han puesto al descubierto varios recintos de planta ovalada y circular pertenecientes a una ocupación más antigua relacionada con la época de transición entre las culturas Paracas 
y Nasca (Nasca Inicial). En las capas inferiores — siempre en capas de relleno— también se encontró algunos fragmentos de cerámica de la época Nasca Tardío (Nasca 7) junto con aquellos del Horizonte Medio pero no se han identificado restos de construcciones de ese tiempo.

Por otro lado, en la parte central y más alta del sitio, donde se encuentran los restos de diversos recintos de planta rectangular y patios más grandes, se estableció otra unidad de excavación que comprendía dos recintos de planta casi circular y pequeños espacios adyacentes que, a su vez, se encuentran al interior de un recinto más grande de planta rectangular (Fig. 16). ${ }^{38}$ Uno de los recintos (UA-1) era reutilizado como vivienda temporal y el otro (UA-2) había sido desmontado hasta el nivel del suelo.

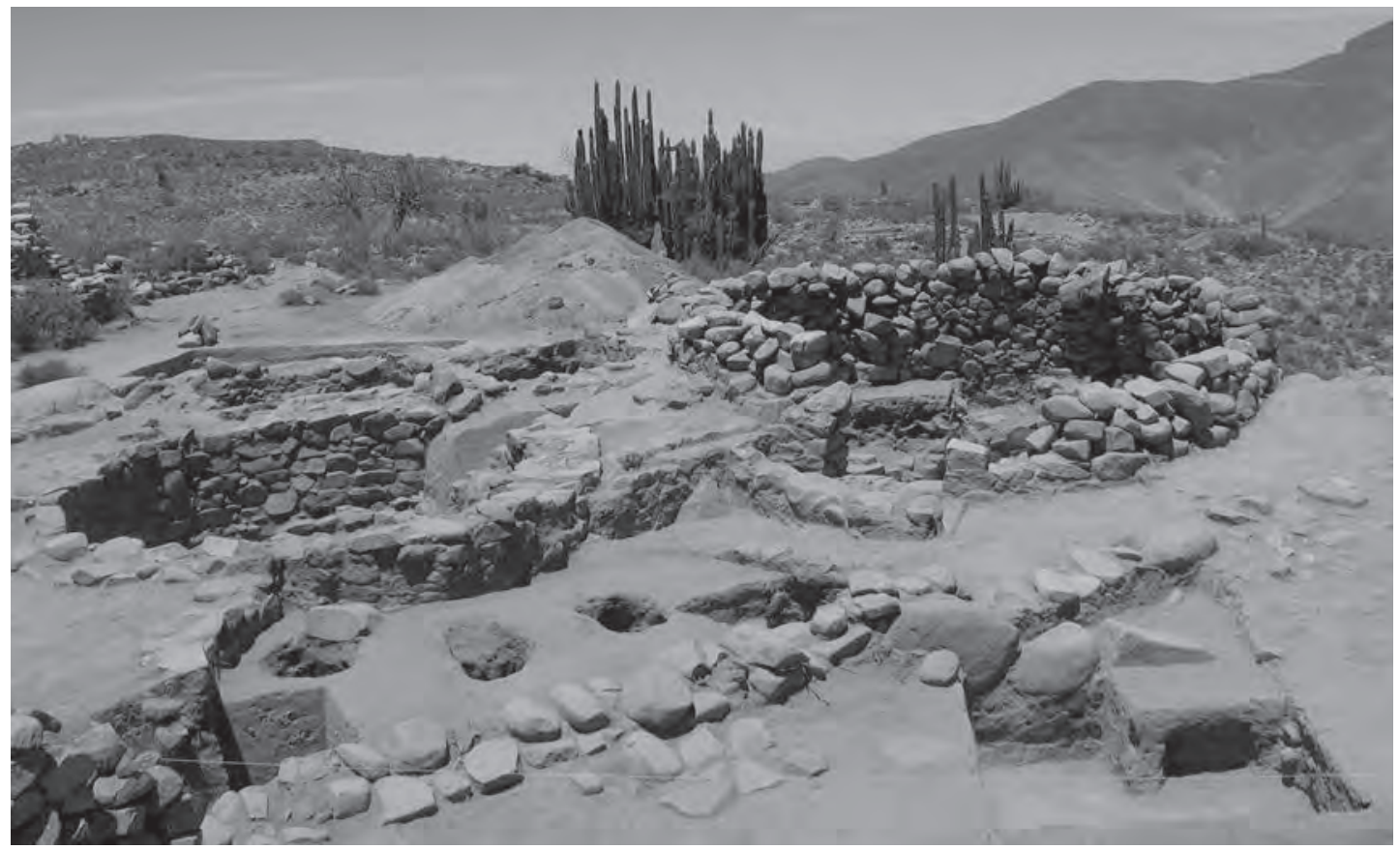

Figura 16. Vista general de las excavaciones en Huayuncalla, con exposición de dos recintos de planta circular excavados en la parte más alta del sitio.

Las excavaciones al interior de uno de los recintos circulares (UA-1) pusieron al descubierto, debajo de una gruesa capa de relleno de tierra y piedras, una cámara funeraria de forma rectangular excavada en la capa natural, la cual estaba delimitada con muros de piedra y un piso de lajas. Una escalera de tres escalones permitía el acceso a la cámara. Al fondo, en la parte central del piso, había otra pequeña cámara de forma cuadrangular que en parte se encuentra debajo de una parte del piso de lajas, la cual estaba rellenada con tierra más fina. En el relleno superior, entre la tierra y las piedras, se encontró cinco vasijas que fueron colocadas juntas en el relleno, dos de las cuales representan felinos modelados. ${ }^{39}$ Asimismo, en forma dispersa en el relleno se encontraron los restos óseos fragmentados e incompletos de 22 individuos humanos, así como fragmentos de varias vasijas pintadas,

38 La mayor parte de las construcciones en la parte central y alta del sitio han sido desmontadas o parcialmente destruidas en tiempos recientes por los pobladores de la zona, quienes utilizaron las piedras de los muros en la construcción de corrales para sus animales.

39 Estas vasijas presentan formas y rasgos distintos a los estilos del Horizonte Medio y al parecer se trata de vasijas dejadas como ofrenda durante la época Colonial. Todo indica que este recinto y la cámara funeraria fue saqueada en ese tiempo. 
puntas de obsidiana y diversos objetos de cobre (tupus, agujas e idolillos). Finalmente, sobre el piso de lajas se encontraron otros dos tupus de cobre y un pequeño disco de oro laminado. Según los rasgos observados, la cámara funeraria fue saqueada algún tiempo después del Horizonte Medio, tiempo en el cual se dejaron las vasijas de ofrenda arriba indicadas.

Las excavaciones en el otro recinto circular -que en realidad tiene casi forma de D- (UA-2) también pusieron al descubierto, luego de retirar tres capas de relleno, una cámara interior de forma circular excavada en la capa natural, a la cual se entraba por un acceso que había sido clausurado con una gran laja. Al nivel de la superficie de esta cámara había un piso de lajas que delimitaba el contorno de la misma, el cual se había establecido sobre la superficie de la capa natural. En el relleno sobrepuesto a este piso, se hallaron dos cráneos humanos de individuos adultos, así como otros huesos incompletos de otros individuos. Cerca del acceso se había colocado otros dos individuos que habrían fungido de guardianes de la cámara funeraria.

Al interior de la cámara, en el relleno superior, se encontraron los restos incompletos de otros tres individuos (dos infantes y un joven), los cuales tenían tupus, agujas y estólicas de cobre como ofrenda. En un nivel intermedio, siempre en una capa de relleno, se encontró una concentración de cráneos y huesos largos humanos pertenecientes a 14 individuos incompletos de diferentes edades, cuyas ofrendas estaban compuestas por tupus, agujas y pequeñas propulsores de estólicas de cobre, así como una lámina circular de oro que tenía motivos repujados. Finalmente, al fondo de la cámara y adosado a uno de los lados del paramento interior, se expuso un pequeño espacio de forma trapezoidal formada por dos pequeños muretes de barro y una piedra ovalada, en cuyo interior se encontraban los restos de otros tres individuos (un infante, un joven y un adulto), cuyas ofrendas incluyen diversos objetos de cobre (discos, agujas y propulsores de estólicas) y puntas de obsidiana (Fig. 17).
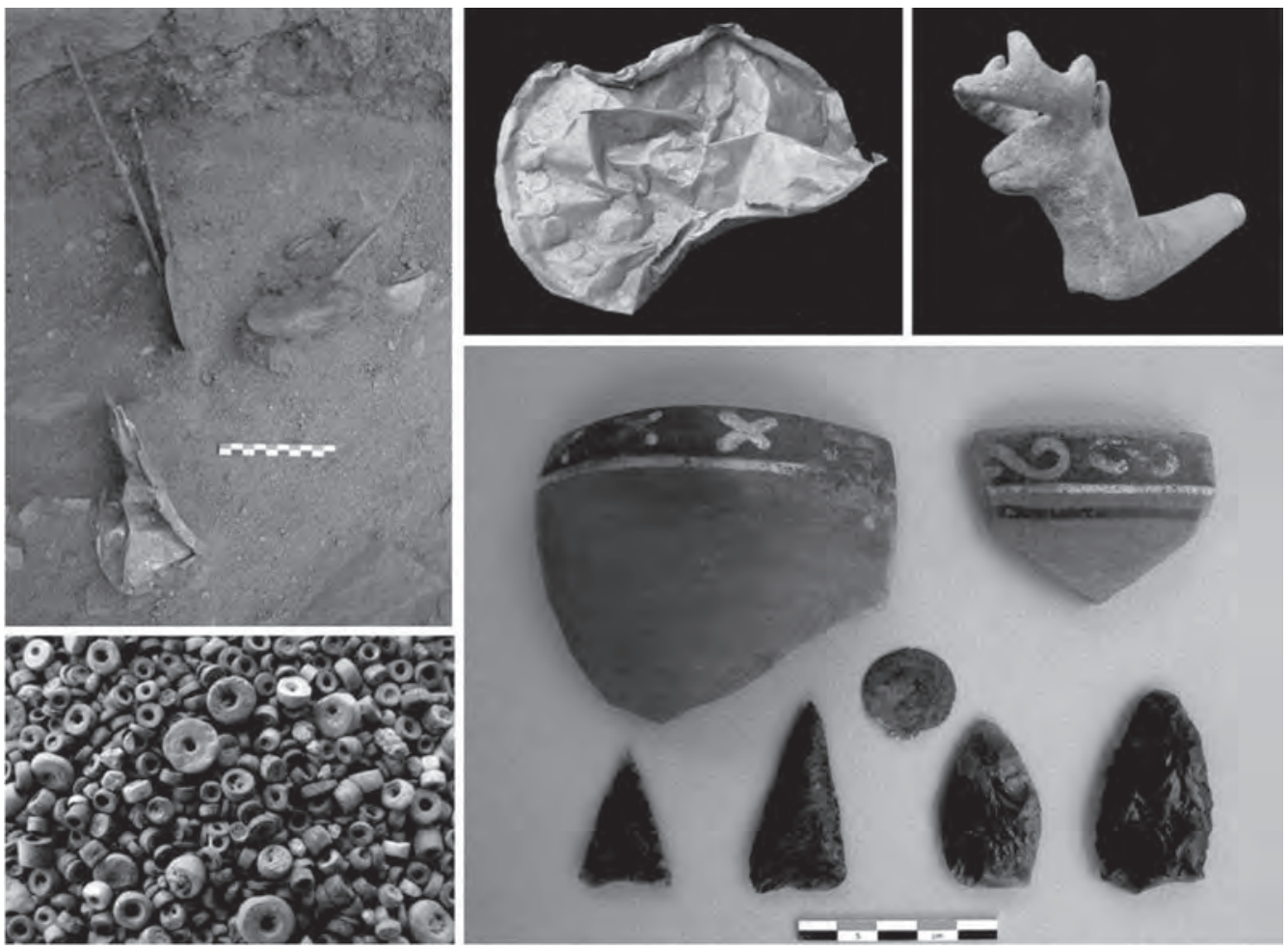

Figura 17. Diversos objetos encontrados en las excavaciones en el sitio de Huayuncalla, donde había muchos objetos de cobre y puntas de obsidiana. 
Como se puede ver, las excavaciones en la parte más alta del sitio pusieron al descubierto construcciones arquitectónicas de aparente uso público y ceremonial, en donde al parecer se llevaron a cabo actividades especiales relacionadas con el culto y el ritual mortuorio. Así lo sugiere el descubrimiento de los numerosos entierros humanos completos, otros mutilados, incompletos, fragmentados y quemados. De momento, mientras se realizan los análisis respectivos, aquí solo queda indicar que estas evidencias datan de la época 2 del Horizonte Medio, la cual en algunas partes de sobrepone a una ocupación doméstica de filiación Nasca (Nasca 5 y Nasca 7).

Finalmente, una cuarta unidad de excavación fue establecida en la parte norte del sitio, en donde se encuentran tres grandes estructuras de piedra de evidente uso funerario. Dos de ellas, una más grande que la otra, presentan cámaras funerarias interiores que tienen techos construidos en forma de falsa bóveda..$^{40}$ La excavación se limitó a la tercera estructura funeraria, la cual estaba intacta pero seriamente afectada por las raíces de un árbol de pati. Las excavaciones allí pusieron al descubierto un recinto de planta rectangular dividido en cuatro cámaras interiores. En la cámara más grande se encontraron los restos óseos de seis individuos incompletos y una vasija llana, mientras que en la cámara adyacente se hallaron otras diez vasijas con formas y decoración típicas de la época 2 del Horizonte Medio (Fig. 18). La tercera cámara contenía sólo algunos huesos sueltos e incompletos de dos individuos y un grupo de pequeñas cuentas hechas con piedras semi-preciosas, mientras que la cuarta cámara fue totalmente afectada por las raíces del árbol y al parecer sólo estaba rellenada.

\section{DiscuSión Y COMENTARIOS FINALES}

Una de las ventajas que brinda el desarrollo de investigaciones sistemáticas y a gran escala, en un territorio a su vez bastante amplio como los llevados a cabo en los valles de Palpa, incluyendo sus componentes costeños y serranos, es la posibilidad de registrar y documentar una gran variedad de evidencias arqueológicas que nos ayuden a explicar los procesos culturales y los cambios ocurridos en ellos a través del tiempo. También el estudio del paisaje y del medio ambiente resulta importante para entender las condiciones en las cuales se produjeron esos eventos. En este sentido, ambas situaciones se han conjugado en las investigaciones del Proyecto Nasca-Palpa (Palpa-Lucanas para la zona de la sierra) para entender las condiciones en las que ocurrió la ocupación Wari en la región y las características que ésta tuvo durante el Horizonte Medio.

En principio, los estudios del paleoclima realizados en los valles de Palpa - tanto en la costa como en la sierra - indican que hacia finales del desarrollo de la cultura Nasca, alrededor del año 600 d.C., la región estaba afrontando un proceso de aridez cada vez más intenso que alcanzó su nivel más crítico durante el Horizonte Medio (Eitel et al. 2005; Eitel y Mächtle 2009; Mächtle y Eitel 2013). En estas condiciones habría ocurrido el colapso de la estructura sociopolítica Nasca, cuyos habitantes abandonaron la parte media de los valles y buscaron establecerse valle arriba, en donde el acceso al agua era más seguro. Sitios como Parasmarca y Huaraco son ejemplos de este movimiento, el cual alcanzó hasta la sierra misma, entre los 2500 y $3500 \mathrm{msnm}$, en donde se han registrado varios sitios Nasca Tardío. Esta situación coincidió con la llegada de colonos Wari a la zona, los cuales al parecer se establecieron en la parte alta de los valles, desde donde sucesivamente iniciaron su incursión a los valles costeños.

A diferencia de los valles de Palpa, en donde casi no se han registrado asentamientos Wari sino tan solo unos pocos sitios de vivienda, tumbas aisladas y cementerios, en los valles de Nasca hubo una mayor cantidad de sitios durante todo el Horizonte Medio y en especial durante la primera época de ese periodo. Esto es particularmente más evidente en el valle de Las Trancas, en donde se localizan sitios como Huaca del Loro y Los Médanos, los cuales fueron establecidos cerca de los famosos puquios

40 Las dos estructuras funerarias estaban saqueadas y en el interior se observa los restos óseos incompletos de varios individuos. 

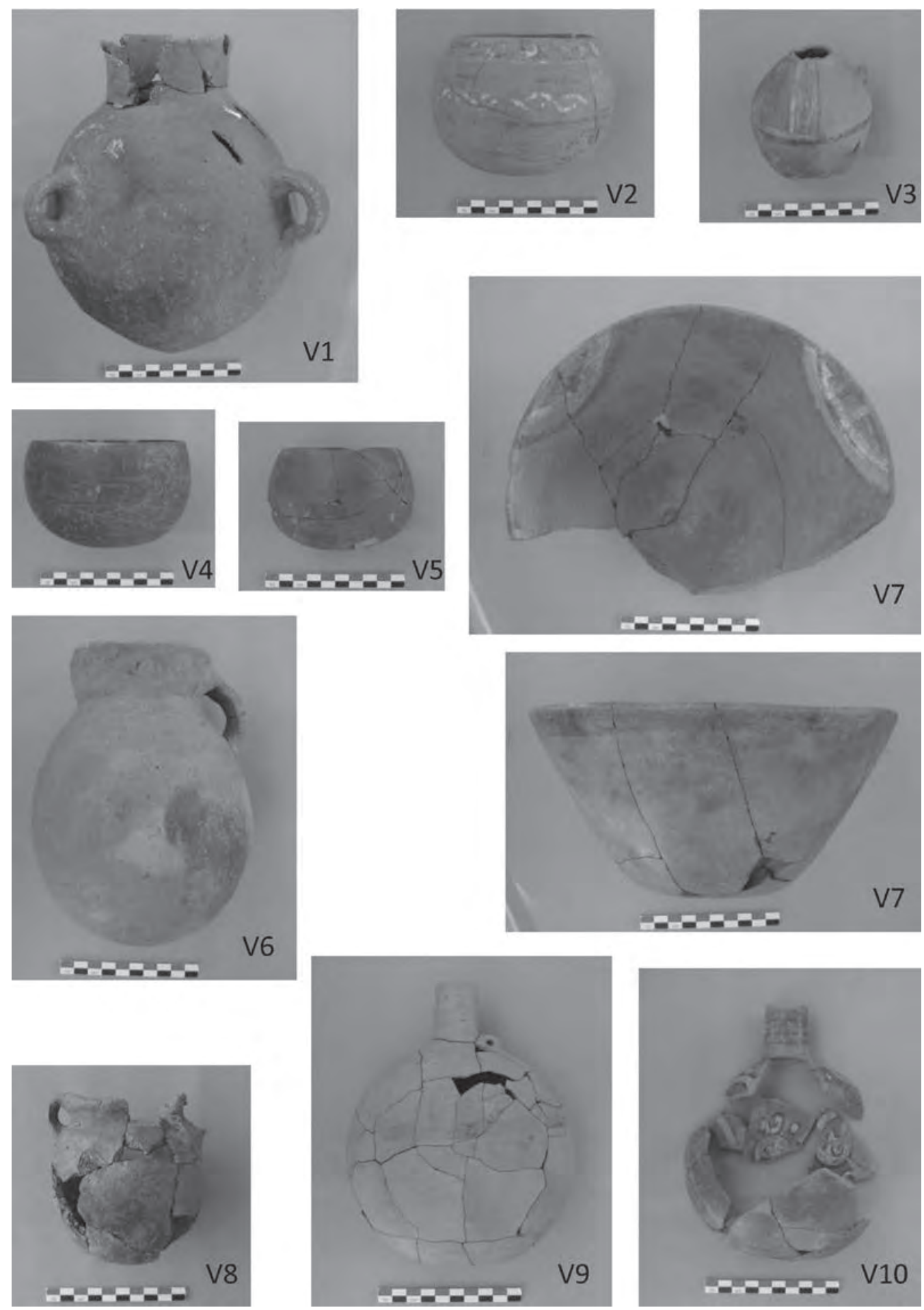

Figura 18. Vasijas de cerámica dejadas como ofrenda en una de las cámaras que compone la estructura funeraria. Las fracturas y la erosión de la decoración se deben a la presión del relleno y a la filtración de agua. 
o acueductos de Nasca, de donde sus habitantes pudieron obtener agua del subsuelo para afrontar las sequías cada vez más prolongadas. Sitios de primer nivel como Huaca del Loro y Pacheco, considerados como la capital local y foránea durante ese tiempo respectivamente (Schreiber 2001), ${ }^{41}$ habrían alcanzado esa categoría justamente debido a la existencia de varios puquios cercanos a su área de influencia.

Durante la época 2 del Horizonte Medio nuevamente se observa una notable ausencia de sitios Wari en los valles de Palpa, en donde parece que el sitio de Lambrasniyoq tuvo el rol predominante al menos desde el punto de vista religioso, toda vez que allí se encuentra la única estructura arquitectónica en forma de D registrada en la entrada a los valles de la costa. Es posible que también el sitio de Huaraco haya tenido un rol semejante pero en este caso se necesita realizar más excavaciones para definir el tipo de ocupación y la función que tuvo. En este mismo tiempo los sitios de Pacheco y Pataraya tuvieron el rol de sitios principales en los valles de Nasca.

En cambio, las evidencias de ocupación Wari en las nacientes de los valles de Palpa (en la sierra misma) son más numerosas y variadas, entre las que destacan diversos tipos de asentamientos, tumbas aisladas, cementerios, corrales y terrazas de agricultura. Todo esto indica que la ocupación Wari en la parte alta de los valles de Palpa era más segura y estable durante el Horizonte Medio, situación que estaba garantizada por la existencia de fértiles abanicos de campos de cultivo, zonas de pastoreo y disponibilidad de agua superficial durante todo el año. En este sentido, el sitio de Mauka Llaqta parece haber tenido el rol centro político más importante de la época, situación que investigaremos en el futuro. De momento, las evidencias descubiertas en Huayuncalla muestran claramente que se trata de un asentamiento importante que fue ocupado durante un buen lapso de tiempo (al menos durante toda la época 2 del Horizonte Medio), en donde además de las actividades cotidianas se realizaron diversas actividades productivas y religiosas o de carácter ceremonial.

En este punto, conviene indicar que esta zona presenta un proceso cultural fuertemente integrado con la costa desde finales del período Formativo, el cual evidentemente fue aprovechado por los Wari para ocupar la zona y establecer enclaves coloniales en la entrada a los valles de la costa, a través de los cuales pudo acceder a recursos como el algodón, maíz y menestras, así como también a las ricas fuentes de arcilla y pigmentos minerales. Justamente en la zona se han registrado dos caminos de larga distancia que descienden hacia la costa por las mesetas y lomas altas que se encuentran entre los poblados de Llauta y Laramate, desde donde luego bajan hacia la costa por los valles de Palpa y Viscas.

Las evidencias registradas en los valles de Palpa, tanto en la zona de costa como de sierra, muestran claramente los modelos de control político, económico y religioso ejercidos por los Wari en su penetración a la costa (Schreiber 2001). En este sentido, las evidencias documentadas hasta hoy indican que la costa sur, y de modo especial la cuenca del Río Grande, jugó un rol importante en las estrategias de expansión y desarrollo del estado Wari, lo que le permitió el acceso y control de recursos no existentes en la región de Ayacucho. Los resultados de las excavaciones en Pataraya, un pequeño enclave Wari de la época 2 del Horizonte Medio en la parte media-alta del valle de Nasca (Edwards 2010), confirman esta observación y ayudan a entender mejor el interés que tuvo Wari para ocupar los valles de Palpa y Nasca.

41 El sitio de Estaquería, ubicado en el valle medio de Nasca, también presenta evidencias de una importante ocupación Wari relacionada con las épocas 1 y 2 del Horizonte Medio, las cuales indican que tuvo tenido un rol especial en la jerarquía de asentamientos. 


\section{Agradecimientos}

Los resultados presentados en este artículo derivan de las investigaciones interdisciplinarias realizadas en el marco de en marco de los proyectos arqueológicos Nasca-Palpa y Palpa-Lucanas, los cuales son auspiciados por el Ministerio Federal de Educación e Investigación de la República Federal Alemana (BMBF) y la Comisión de Arqueología para Culturas Extraeuropeas (KAAK) del Instituto Arqueológico Alemán (DAI). Los trabajos de campo y las investigaciones del proyecto Nasca-Palpa han sido debidamente autorizadas por el entonces Instituto Nacional de Cultura (INC). También queremos expresar nuestro especial agradecimiento a todos los participantes peruanos y extranjeros que colaboraron en las excavaciones y en el análisis de los materiales de los sitios incluidos en este artículo, de modo especial a Judith Astuhuamán, arqueóloga peruana que estuvo presente en casi todos los sitios. 


\section{BiBLIOGRAFÍA}

CARMICHAEL, Patrick H.

1995 "Nasca Burial Patterns: social structure and mortuary ideology". En: T.D. Dillehay (ed.) Tombs for the living: Andean Mortuary Practices, pp. 161-187. Washington, D.C.: Dumbarton Oaks Research Library and Collection.

CONLEE, Christina A.

2011 "An exploration of looted Middle Horizon tombs from Nasca". En: Ñawpa Pacha, Journal of Andean Archaeology. 31(1): 45-54. Berkeley: Institute of Andean Studies.

COOK, Anita

2001 "Huari D-Shaped Structures, Sacrificial Offerings and Divine Rulership". En: E. P. Benson y A. G. Cook (eds.) Ritual Sacrifice in Ancient PeruWari Iconography, Mortuary Cults, and D-shaped Structures. Austin: University of Texas Press.

DOERING, Heinrich U.

1958 "Berich über archaologische Feldarbeiten in Perú". En: Ethnos 23 (2-4): 67-99. Estocolmo.

EDWARDS, Matthew J.

2010 Archaeological Investigation at Pataraya: A Wari Outpost in the Nasca Valley of Southern Peru. Ph.D., dissertation, University of California, Santa Barbara.

EITEL, B., S. HECHT, B. MÄCHTLE, G. SCHUKRAFT, A. KADEREIT, G. A. WAGNER, B. KROMER, I. UNKEL y M. REINDEL

2005 "Geoarchaeological Evidence from Desert Loess in the Nazca-Palpa Region, Southern Peru: Paleoenviromental changes and their impact on Pre-Columbian cultures". En: Archeometry 47 (1): 137-158.

EITEL, Bernhard y Bertil MÄCHTLE

2009 "Man and Environment in the Eastern Atacama Desert (Southern Peru): Holocene Climate Changes and Their Impact on Precolumbian Cultures". En: M. Reindel y G. Wagner (eds.) New Technologies for Archaeology, pp. 17-37. Natural Science in Archaeology. Springer-Verlag Berlín Heildelberg.

ISLA C., Johny

2001 "Wari en Palpa y Nasca: Perspectivas desde el punto de vista funerario". En: P. Kaulicke, W. Isbell (eds.) Boletín de Arqueología PUCP 5: 555-583. Lima: PUCP.

2009 "From Hunters to Regional Lords: Funerary Practices in Palpa, Peru". En: M. Reindel y G. Wagner (eds.) New Technologies for Archaeology: Multidisciplinary Investigations in Palpa and Nasca, Peru, pp. 119-139. Natural Science in Archaeology. Springer-Verlag Berlín Heildelberg.

2010 "Perspectivas sobre el proceso cultural en los valles de Palpa, costa sur del Perú". En: L. Valle (ed.) Arqueología y Desarrollo. Experiencias y Posibilidades en el Perú, pp. 15-52. Trujillo: Ediciones SIAN.

ISLA C., Johny y Markus REINDEL

2006 "Burial Patterns and Sociopolitical Organization in Nasca 5 Society". En: W. H. Isbell y H. Silverman (eds.) Andean Archaeology III: North and South, pp. 374-400. New York.

LAMBERS, Karsten

2006 The geoglyphs of Palpa, Peru: Documentation, analysis and interpretation. Ph.D. thesis. Forschungen zur Archäologie Aussereuropäischer Kulturen 2. Aichwald.

KNOBLOCK, Patricia

1983 A Study of the Andean Huari Ceramics from the Early Intermediate Period to Middle Horizon Epoch 1. Ph.D., dissertation. Department of Anthropology, State University of New York at Binghamton.

MÄCHTLE, Bertil y Bernard EITEL

2013 "Fragile landscapes, fragile civilizations - How climate determined societies in the pre-Columbian south Peruvian Andes". En: Catena 103: 62-73.

MENZEL, Dorothy

1964 "Style and time in the Middle Horizon". En: Ñawpa Pacha 2: 1-105. Berkeley: Institute of Andean Studies.

1968a La Cultura Huari. Lima: Compañía de Seguros Peruano-Suizo. 
1968b "New data on the Huari empire in Middle Horizon Epoch 2a". En: Ñawpa Pacha 6: 47-114. Berkeley: Institute of Andean Studies.

1971 "Estudios Arqueológicos en los Valles de Ica, Pisco, Chincha y Cañete". En: Arqueología y Sociedad 6. Lima: Museo de Arqueología y Etnología de la Universidad Nacional Mayor de San Marcos.

NEÜDECKER, Angelika

1979 Archäologische Forschungen im Nazca-Gebiet, Perú. Das Tal des Río Santa Cruz in praespanischer Zeit aus der Sicht der Forschungen Professor Dr. Ubbelohde-Doerings im Jahre 1932. Münchner Beiträge zur Amerikanistik, 3. Klaus Renner Verlag, Hohenschäftlarn.

REINDEL, Markus

2009 "Life at the Edge of the Desert - Archaeological Reconstruction of the Settlement History in the Valleys of Palpa, Peru". En: M. Reindel y G. Wagner (eds.) New Technologies for Archaeology, pp. 439461. Natural Science in Archaeology. Springer-Verlag Berlín Heildelberg.

REINDEL, Markus; Johny ISLA C.

2001 "Los Molinos und La Muña. Zwei Siedlungszentren der Nasca-Kultur in Palpa, Südperu”. Beiträge zur Allgemeinen und Vergleichenden Archäologie 21: 241-319. Verlag Philipp von Zabern, Mainz.

REINDEL, Markus; Johny ISLA C.; Karsten LAMBERS

2006 "Altares en el desierto: Las estructuras de piedra sobre los geoglifos Nasca en Palpa". En: Arqueología y Sociedad 17: 179-222. Lima: Museo de Arqueología y Antropología, UNMSM.

SCHREIBER, Katharina J.

2001 "Los Wari en su Contexto Local: Nasca y Sondondo". En: P. Kaulicke y W. Isbell (eds.) Huari y Tiwanaku: Modelos vs. Evidencias, Primera Parte, Boletín de Arqueología PUCP 4: 425-447, Lima.

SILVERMAN, Helaine I.

1988 "Nasca 8: A Reassessment of Its Chronological Placement and Cultural Significance". En: Virginia J. Vitzthum (ed.) Multidisciplinary Studies in Andean Anthropology, pp. 23-32. Michigan Discussion in Anthropology 8. Departament of Anthropology, University of Michigan, Ann Arbor.

SILVERMAN, Helaine I. y Donald PROULX

2002 The Nasca. The Peoples of America. Blackwell Publishers.

STRONG, William D.

1957 Paracas, Nazca, and Tiahuanacoid Cultural Relationships in South Coastal Peru. Memoirs of the Society for American Archaeology 13. The Society for American Archaeology, Salt Lake City, Utah.

TELLO, Julio César

1917 "Los Antiguos Cementerios del Valle de Nazca". En: G. L. Swiggett (ed.) Proceedings of the Second Pan American Scientific Congress, vol. I: 283-291. Washington D.C.: Government Printing Office.

TELLO, Julio C. y Toribio MEJÍA XESSPE

1967 "Historia de los Museos Nacionales del Perú 1822-1946". En: Arqueológicas 10, 268 pp. Museo Nacional de Antropología y Arqueología e Instituto y Museo de Arqueología de la Universidad Nacional Mayor de San Marcos, Lima. 